\title{
Hypothesis for a Risk Cost of Carbon: Revising the Externalities and Ethics of Climate Change
}

\author{
Delton B. Chen, Joel van der Beek, and Jonathan Cloud
}

\begin{abstract}
Standard market-based policies for addressing climate change mostly aim to internalize the Social Cost of Carbon (SCC) into the economy with either carbon taxes or cap-and-trade schemes. Standard policies are failing to manage the systemic risk of dangerous-to-catastrophic climate change for a variety of reasons. In this chapter we clarify and expand on a market hypothesis that argues for a second externalized cost of carbon, called the Risk Cost of Carbon (RCC), as the appropriate solution to this risk problem.

The combination of the SCC and RCC creates a new paradigm of complementary market pricing for the dual objectives of improving market efficiency and managing systemic risk, respectively. Introducing the RCC addresses the problem of how to decouple gross world product (GWP) from carbon emissions and how to solve the paradox of time discounting under systemic risk. Subsequently the RCC could have major implications for climate change economics, public policy, and sustainability theory. The hypothesis is novel by taking into consideration both the entropy and the mass of the carbon budget.

The RCC is technically defined as the cost of imposing risk tolerances (\%) on climate mitigation objectives, and it has units of USD per tonne of carbon dioxide equivalent $\left(\mathrm{CO}_{2} \mathrm{e}\right)$ mitigated. The RCC is internalized with a "global carbon reward" that manages a trade-off between market efficiency and climate certainty. The carbon reward is issued as a parallel currency and with an exchange rate that is managed by central banks over a rolling 100-year planning horizon. A key recommendation is to test the hypothesis with experiments.
\end{abstract}

Keywords Climate change $\cdot$ Systemic risk $\cdot$ Risk management $\cdot$ Carbon price . Biophysical $\cdot$ Thermodynamics $\cdot$ Entropy $\cdot$ Central bank $\cdot$ Monetary policy $\cdot$ Parallel currency $\cdot$ Macroprudential

\footnotetext{
D. B. Chen $(\varangle) \cdot$ J. Cloud

Center for Regenerative Community Solutions (501c3 Non-Profit), Basking Ridge, NJ, USA

e-mail: deltonchen@crcsolutions.org

J. van der Beek

EconoVision \& EconoLytics, Doorn, Utrecht, The Netherlands
} 


\section{Introduction}

The topic of this chapter is the theoretical plausibility of a second externalized cost of anthropogenic greenhouse gas (GHG) emissions, called the Risk Cost of Carbon (RCC), whereby the first externalized cost is already established as the Social Cost of Carbon (SCC). Chen et al. (2017) originally postulated the existence of the RCC, which they describe as the cost of managing climate risk with positive incentives guided by cost-effectiveness analysis. The possible existence of the RCC is explained with the Holistic Market Hypothesis (HMH), which Chen et al. (2017) introduced using an epistemology of complementary relationships. The HMH could have major implications for economic assessments, climate policy, and environmental law because it posits that the total externalized cost of the market failure is significantly underestimated when the RCC is ignored.

To understand why risk can be quantified as a cost—-such as with the RCC - it is necessary to accept that risk is the "effect of uncertainty on objectives" (ISO 2009). The RCC is the cost of reducing the uncertainty of achieving specific climate mitigation objectives, whereby the targeted levels of uncertainty are the acceptable probabilities (\%) of success or failure. The targeted levels of uncertainty may also be called "risk tolerances", and the risk tolerances are used to estimate the additional mass of carbon dioxide equivalent $\left(\mathrm{CO}_{2} \mathrm{e}\right)$ to be mitigated.

The $\mathrm{HMH}$ involves an interdisciplinary interpretation of carbon taxes and rewards, including an analysis of their economic objectives and their qualitative effect on the entropy of carbon in the environment. The topic of entropy is relevant because it is used to resolve a handful of temporal paradoxes that accompany the standard policy toolkit for climate mitigation. The HMH involves terminology from both neoclassical economics and physics, and this may pose a challenge because economists and physicists typically use different conceptual models, methods, and terminology. The HMH is presented as a macroscopic entropic theory, and if it is cogent and correct, then it should be possible to validate it with experiments and verify it with a statistical-mechanical approach.

To guide the reader, the chapter begins with an introduction to the SCC and RCC (Sect. 1.1). Principles and concepts that support the $\mathrm{HMH}$ are described, including climate systemic risk, positive carbon pricing, thermodynamic laws, carbon emissions, and network theory (Sect. 1). The HMH is stated in Sect. 2 in terms of temporal relationships and the RCC metric. In Sect. 3, a policy for a global carbon reward is described that can internalize the RCC into the economy. In Sect. 4, an epistemology of complementary-and-opposite relationships is applied to the carbon tax to verify that the SCC and the RCC are complementary. In Sect. 5, the theoretical utility of the RCC is discussed in terms of solving a temporal paradox, and the practical utility of the global carbon reward is discussed in terms of the Paris Climate Agreement (COP21), net zero emissions, global growth, and ethics. In Sect. 6, some concluding remarks are provided, and finally, in Sect. 7, recommendations are given for future research. For reasons of brevity, the political feasibility of climate policies is not discussed. 


\subsection{Externalized Cost of Carbon}

The Social Cost of Carbon (SCC) is a negative externality created by anthropogenic GHGs, and it is typically defined as the time-discounted marginal loss in economic welfare that results from 1 metric tonne of carbon dioxide equivalent $\left(\mathrm{CO}_{2} \mathrm{e}\right)$ emitted in a given year (e.g., IAWG 2013). Carbon taxes, which are a kind of Pigovian tax, can be used to internalize the SCC into the economy. Other market-based policies can also be used to incentivize emissions reductions, including cap-and-trade schemes. The ideal carbon tax is related to the SCC under cost-benefit analysis, and consequently the SCC is important in the study of climate change economics (Nordhaus 1991, 2017; Stern 2007).

Despite decades of research into the SCC (e.g., U.S. President 1981), the scholarship on carbon pricing has not associated a specific objective with offering global rewards for climate mitigation. If global rewards for carbon represent an unused price signal, then two fundamentally important questions deserve our attention, namely:

Q1. What is the financial mechanism for a global carbon reward?

Q2. What is the economic objective of a global carbon reward?

Chen et al. (2017) claim that-based on their Holistic Market Hypothesis (HMH) - a global reward for carbon mitigation can (1) be provided with monetary policy and (2) can be used to manage climate systemic risk. Aglietta and Espagne (2016) originally coined the term "climate systemic risk" in reference to financial and physical fragilities associated with anthropogenic climate change (refer Sect. 1.3). If these answers to the two questions are correct, then a third question arises:

Q3. What is the total externalized cost of carbon emissions?

Chen et al. (2017) postulate that (3) the total externalized cost of carbon emissions is the SCC plus a second externality, called the Risk Cost of Carbon (RCC). The RCC is the assessed cost of providing a positive externality and it does not substitute for the SCC, which is the assessed cost of a negative externality. They define the $\mathrm{RCC}$ as follows:

...the market price of each metric tonne of additional $\mathrm{CO}_{2}$-e mitigation service that is needed to reduce climate systemic risk to an agreed limit. (p. 41)

\subsection{Positive Carbon Price}

The literature lacks clear terminology for defining a positive carbon price (e.g., Sirkis et al. 2015), and to provide clarity, the terms "positive carbon price," "carbon subsidy," and "carbon reward" are given the following definitions for this exposition:

- A positive carbon price is defined here to be a price signal that offers payment for mitigating carbon emissions-for abating emissions and for removing carbon 
from the atmosphere ${ }^{1}$ — and with the payment being divorced from carbon offsetting schemes.

- A carbon subsidy is defined here to be a positive carbon price that is offered as an ex post or ex ante payment and when the payment is made with a national fiat currency or as a tax deduction.

- A carbon reward is defined here to be a positive carbon price that is offered as an ex post payment for verified carbon mitigation, and when the reward payment is (a) made with a parallel currency denominated in carbon by mass, and (b) provided with conditions for the awardees to maintain an agreed standard of service.

The above provisional terms may help to open up a wider discourse on positive pricing. According to Chen et al. (2017), the global carbon reward should be implemented as a parallel currency so that monetary policy and currency trading can be used to internalize the RCC into the economy. The global carbon reward generates a positive externality because it acts as preventative climate insurance, and this insurance may be classified as a 'public good' because it yields physical benefits that are non-rivalrous and non-excludable. The global carbon reward is a macroprudential responsibility of central banks, and this responsibility should be insulated from political interference. In the following section, we will examine the concept of "climate systemic risk," which is used to define the objective of the global carbon reward and the macroprudential agenda.

\subsection{Climate Systemic Risk}

Aglietta and Espagne (2016) describe "climate systemic risk" as the ensemble of financial and physical fragilities produced by greenhouse emissions, whereby "fragility" is the possibility of an unacceptable systemic failure. The actual impacts of a systemic failure may not be known with confidence, and so an emphasis is placed on assessing the probability of a systemic failure rather than trying to predict the quantity of the damages. One example of a climate systemic risk is the possibility that $2.0^{\circ} \mathrm{C}$ of global warming will be exceeded by the year 2100 . The international ambition to limit this climate systemic risk is a major inspiration for the Paris Climate Agreement (UNFCCC 2015).

Aglietta and Espagne (2016) equate the climate systemic risk with the cost of preventative insurance, whereby the cost is "...equivalent of a value that society attributes to mitigation activities" (p. 5). Aglietta and Espagne (2016) also link their insurance proposal to central banks and monetary policy as follows:

\footnotetext{
${ }^{1}$ The positive carbon price does not address geo-engineering of the solar energy balance.
} 
The incorporation of some kind of climate signal in monetary policy and financial stability oversight is required, not because the central banks should be a direct actor of the low-carbon transition, but as part of their financial stability mandate. (p. 18)

Aglietta and Espagne (2016) suggest that climate systemic risk can form the basis of a new hypothesis that differs from the traditional theory for externalized costs:

The climate systemic risk hypothesis radically departs from the premises of standard externality theory. It suggests that we might want to drastically diminish the probability of occurrence of some very bad outcomes for society, which might lead to its quasi-destruction. (p. 13)

Chen et al. (2017) claim that a global reward for carbon mitigation is a kind of preventative insurance against unwanted global warming and that it has similarity with payments for ecosystem services (PES) and is analogous to preventative health insurance. Aglietta and Espagne (2016) and Chen et al. (2017) both justify their collective insurance proposals, but they use somewhat different reasoning. Aglietta and Espagne (2016) emphasize the Radical Uncertainty Hypothesis (e.g., Knight 1921; Keynes 1921) and climate fragility as key justifications, whereas Chen et al. (2017) present the Holistic Market Hypothesis (HMH) and the RCC as their justification. The main difference between the two proposals is that Aglietta and Espagne (2016) recommend a break from the standard model for externalized costs, whereas Chen et al. (2017) present the RCC as an augmentation to the standard model. In the following sections, we will review the key biophysical concepts underpinning the $\mathrm{HMH}$.

\subsection{Biophysical Economics}

Biophysical economics is an emerging school of economic thought that attempts to understand the economy using the laws of thermodynamics (e.g., Cleveland 1987). A key strength of the biophysical approach is that the laws of thermodynamics are applicable to all biophysical systems, including to civilization, the climate system, and living organisms. Despite its solid theoretical foundation, biophysical economics is currently only a minor school because it is philosophically at odds with the classical/neoclassical worldview that economic activity is driven by human agency. For example, a commonly cited definition of classical economics is based on Robbins' (1935) review of the subject, as follows:

Economics is the science which studies human behavior as a relationship between ends and scarce means which have alternative uses. (p. 16)

A distinctive feature of the Holistic Market Hypothesis (HMH) is its acceptance of both the classical/neoclassical approach of studying human behavior, and the biophysical approach of studying energy dissipation as the universal source of all kinds of agency. Under the $\mathrm{HMH}$, the biophysical economic worldview that supports the SCC and RCC is considered to be more general than the classical/neoclassical economic worldview that only supports the SCC. This hierarchy of worldviews is relevant when addressing carbon emissions, and the underlying reason is that 
civilization has its own emergent agency because it dissipates energy. This agency can be relatively strong compared with the agency of individuals, social collectives and political groups. The issue of competing agency is especially relevant to the challenge of mitigating carbon emissions, and this is because the primary energy supply, the agricultural sector, and many other economic activities are strongly coupled to carbon. Under the $\mathrm{HMH}$, the expectation is that civilization's agency will undermine attempts to quickly reduce carbon emissions. Under the HMH, it is interpreted that previously successful strategies for mitigating other types of pollution are unlikely to be effective when applied to carbon, and this is because most other pollutants are not strongly coupled to the energy supply (e.g. sulphur in acid rain can be removed, and ozone depleting substances can be substituted).

A unique feature of the HMH is the way that the Second Law of Thermodynamics is used to qualitatively interpret the SCC and RCC as a complementary pair. The two most important laws in thermodynamics are known from the works of Clausius (1854), Maxwell (1860), Boltzmann (1872), and others:

(Law 1) The First Law of Thermodynamics is the conservation law for energy. It states that the energy of a system is conserved because energy cannot be created or destroyed. The First Law is time-symmetric, and energy is an extensive property with units of Joules.

(Law 2) The Second Law of Thermodynamics is the entropy law for matter and energy. The entropy of a classical system is a measure of the "disorder" or randomness of the particles that comprise the system. The Second Law states that the entropy of an isolated system increases monotonically with energy dissipation and eventually peaks at thermal equilibrium. Under the Second Law it is possible for energy dissipation to have reduced the entropy of an open system if the entropy of the open system plus its surroundings has increased. The Second Law is timeasymmetric, and entropy is an extensive property with units of Joules/Kelvin.

The first two laws of thermodynamics were originally derived for gases because gases are relatively simple to study (e.g., Clausius 1867). The First Law may be intuitive to most people, but the Second Law often requires clarification. The Second Law is supported by statistical theories for the randomness of particle interactions (e.g., Maxwell 1860; Boltzmann 1872), and the law explains why heat will flow down a temperature gradient — from hot to cold—but not in the other direction.

The Second Law is vitally important to our understanding of civilization as a type of 'heat engine' that dissipates energy to do the work of producing goods and services while releasing heat and high-entropy waste, such as $\mathrm{CO}_{2}$. For example, the First and Second Laws are used to derive the maximum theoretical efficiency of a cyclic engine that converts heat into mechanical work (i.e., the Carnot heat engine). The Second Law also applies to living cells in terms of explaining the local decrease in entropy within the cell walls: a product of energy dissipation and an increase in the entropy of the environment. England (2013) used the Second Law to develop a probabilistic theory that explains why biological self-replication is favored-thus giving clues to the origins of life.

Civilization and living organisms are similar, because both persist by maintaining a low-entropy condition far from thermodynamic equilibrium. Raworth (2017) 


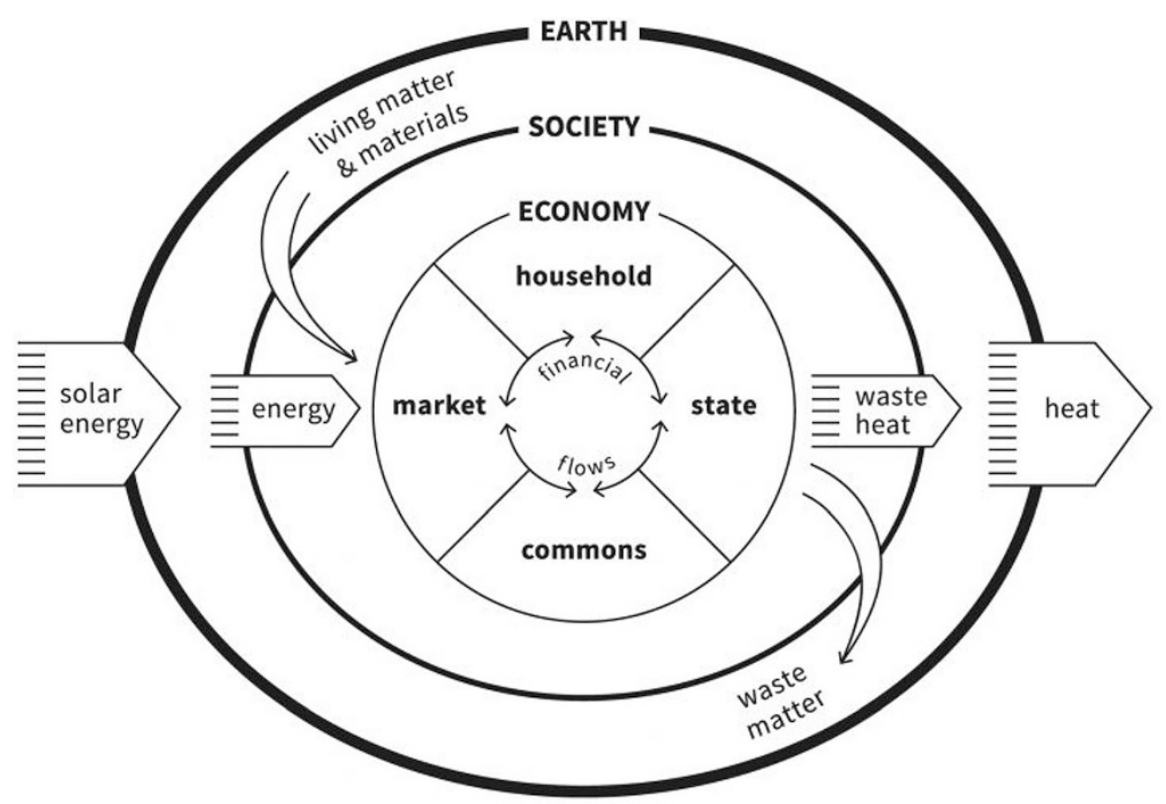

Fig. 1 The embedded economy diagram of Raworth (2017) shows that the economy is part of an open system that dissipates energy and externalizes entropy as waste heat and matter (reproduced with kind permission of the author)

presents the "embedded economy diagram" to illustrate how this condition is maintained in terms of economic processes within civilization (see Fig. 1; note that civilization is synonymous with "society" in Fig. 1). As shown in Fig. 1, civilization is embedded within the Earth's ecosystem. As expected under the Second Law, civilization receives useful energy and low-entropy materials, and it rejects waste heat and high-entropy matter to maintain its low-entropy state. The entropy of civilization is generally too complex to be assessed quantitatively, and in the following discussion entropy is only considered qualitatively.

The economy is an internal process of civilization (refer Fig. 1). Annila and Salthe (2009) present an argument for why the economy is driven by energy dissipation under the Second Law. Garrett $(2011,2012,2014,2015)$ took a major step forward by developing a lumped-parameter model of civilization's energy dissipation that links energy demand and $\mathrm{CO}_{2}$ emissions to cumulative GDP. Such arguments and models highlight that there are two possible sources of economic agency: (a) human agency and (b) energy dissipation. These two sources of agency are a paradox of the neoclassical and biophysical economic perspectives.

There can be no doubting that civilization and all other biophysical systems adhere to the laws of thermodynamics. Despite this thermodynamic certainty, economic processes are inherently difficult to quantify with the Second Law because civilization is far from thermodynamic equilibrium and also because the financial system is a complex informational system. Despite these complexities, various lines of research have revealed that the economy does express biophysical patterns of behavior. For 
example, Kümmel and Lindenberger (2014) found that primary energy supply was a dominant factor in economic production in three major developed economies; and Lawrence et al. (2013) found that the global per capita distributions of energy consumption and carbon dioxide $\left(\mathrm{CO}_{2}\right)$ emissions are converging on a common exponential distribution without being directed to do so using public policies. The $\mathrm{HMH}$ takes a new approach in biophyiscal economics by deriving a policy for a global carbon reward based on a reversal of the carbon tax, whereby the Second Law is used to justify a condition of time-asymmetry in the dominant social agreements/responses that comprise these two policies (refer Sect. 2). Under the Second Law, the change in the entropy of carbon in the environment is expected to be negative as a result of each policy, however the total change in entropy is always positive.

\subsection{Future Carbon Emissions}

A threat to the well-being of future generations is civilization's strong tendency to emit carbon dioxide $\left(\mathrm{CO}_{2}\right)$ and other greenhouse gases while dissipating energy. Raftery et al. (2017) developed a probabilistic model of future $\mathrm{CO}_{2}$ emissions based on country-specific versions of the Kaya identity and extrapolated future temperature changes to the year 2100 . They conclude that the $1.5^{\circ} \mathrm{C}$ and $2.0^{\circ} \mathrm{C}$ limits of the Paris Climate Agreement have a $99 \%$ and $95 \%$ chance of failure, respectively (i.e., $1 \%$ and $5 \%$ chance of success, respectively). Moreover, Raftery et al. (2017) conclude that global warming is trending toward $3.2{ }^{\circ} \mathrm{C}\left(2.0-4.9^{\circ} \mathrm{C}\right)$ by 2100 .

The study of Raftery et al. (2017) highlights that a major driver of global emissions is a rising total gross domestic product (GDP) — or gross world product (GWP)—which is driven higher by rising GDP per capita and rising population. Capacity to reverse the trend appears limited, because future reductions in the carbon intensity of GDP have limitations and because "Policies to reduce GDP per capita seem unlikely..." (p. 3). The probabilities and macroeconomic trends presented by Raftery et al. (2017) are a stark reminder that climate risk is not well managed.

Garrett $(2011,2012)$ developed a lumped-parameter model of civilization to assess its primary energy usage and $\mathrm{CO}_{2}$ emissions. He adopts a biophysical worldview by linking civilization's primary energy consumption to civilization's total wealth, which he represents as the cumulative gross world product (GWP). Garrett (2012) subsequently proposed the following relationship for global $\mathrm{CO}_{2}$ emissions over time:

$$
E(t) \cong c(t) \lambda \sum_{i=1}^{t} \mathrm{GWP}(i)
$$

where $E=$ total mass of $\mathrm{CO}_{2}$ emissions per year; $c=$ average $\mathrm{CO}_{2}$ emissions intensity of energy; $\lambda=$ average power consumption per unit of currency as a time-invariant parameter; GWP $=$ inflation-adjusted gross world product; $t=$ current time in years; and $i=$ time step starting in the pre-industrial period.

Garrett (2012) assessed the historical data for GWP, primary energy, and inflation, to arrive at the following estimate of the mean inflation-adjusted $\lambda$ : 


$$
\lambda=9.7 \pm 0.3 \mathrm{~mW} \text { per USD }(1990)
$$

Garrett (2012) argues that because of a coupling between economic consumption and primary energy, further improvements in energy efficiency will cause civilization to grow faster and to ultimately consume more energy per unit of time. According to Garrett (2012), this coupling is a driver of $\mathrm{CO}_{2}$ emissions and puts humanity in a "double-bind," and so he writes: "If civilization does not collapse quickly this century, then $\mathrm{CO}_{2}$ levels will likely end up exceeding 1000 ppmv..." (p. 1).

In Sect. 5.2 the plausibility of using a global carbon reward to escape from the double-bind problem is examined. The solution involves a currency exchange rate mechanism to create a negative feedback on gross world product (GWP) and dirty patterns of economic growth. Closely related to the problem of unsustainable growth are the problems of energy demand rebound after improvements are made in energy effficiency — called Jevons paradox — and poorly managed human populations. The plausibility of using the global carbon reward to address these two related problems is examined (refer Sects. 5.2.2 and 5.2.3, respectively).

\subsection{Network Theory}

Network theory involves the study of network organization, topology, and lumped parameters, and it is referenced by the HMH because Chen et al. (2017) consider the social agreements and financial flows of climate policies to be biophysical networks. They represent a policy's authority and market actors as nodes and incentive payments as vectors. The elementary nodes and vectors are shown in Fig. 2 and are used in Sect. 4 to describe policies for negative and positive carbon pricing.

The idea that climate policies can be represented as biophysical networks is supported by the comments of Currarini et al. (2014), who found that network theory has utility in developing environmental policy:

Recent research in the field of network economics has shown how explicitly modelling the network structure of social and economic relations can provide significant theoretical insights, as well as account for previously unexplained empirical evidence. Despite their critical importance to many environmental problems, network structures and dynamics have been largely disregarded by the environmental economics literature. (p. 1)

Broadbent and Vaughter (2014) similarly claim that social network analysis (SNA) is a technique that is well suited to the interdisciplinary investigation of

(a)

Authority
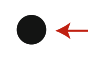

Fig. 2 Elementary nodes and vectors for describing climate policies, such that (a) a negative price, such as a carbon tax, results in a financial flow to the authority and (b) a positive price, such as a carbon subsidy or reward, results in a financial flow to the market actor 
climate policy by integrating ideas from the social and natural sciences. Similar to SNA is actor-network theory (ANT), which considers both human actors and machines as "actants" in the same networks (Law 2009). The thermodynamic analysis of networks was developed independently of SNA and ANT, and according to Oster et al. (1971) "In the [thermodynamic] network approach we 'pull apart' the continuum, revealing the implicit topological relations" (p. 393). They state that network thermodynamics is well defined mathematically but is often neglected, such that "This crucial aspect has been largely neglected in the treatment of thermodynamic systems" (p. 1). The HMH makes use of network theory by referring to climate policies as biophysical networks.

\section{Holistic Market Hypothesis}

The Holistic Market Hypothesis (HMH) of Chen et al. (2017) is a hypothesis that two externalized costs of carbon emissions are created by carbon emissions- the Social Cost of Carbon (SCC) and the Risk Cost of Carbon (RCC) - and that both costs need to be internalized into the economy to manage the climate problem (see Table 1). The hypothesis is that the SCC associates with the (Type I) carbon tax policy, and that the RCC associates with a (Type II) global carbon reward policy. The hypothesis is that each externalized cost is assessed from a unique frame of reference: the SCC is assessed from a (Type I) neoclassical perspective; and the RCC is assessed from a (Type II) biophysical perspective. Moreover, the Type I and Type II policies, tools, and objectives are complementary because they aggregate benefits and will create a synergy effect of improved social cooperation and economic resilience when implemented concurrently. The complementary nature of Type I and Type II policies is described in Sect. 2.3 with a principle called Market Policy Dualism (MPD).

The conceptual model for the HMH requires that the Type I and Type II policies be compared in terms of their common operational objective: to reduce the mass of carbon entering the atmosphere. By restating this operational objective as the reduction of the entropy of carbon within the environment, a connection is made between these policies and the Second Law of Thermodynamics. The entropy of carbon increases when it enters the atmosphere as GHGs, because carbon in this gaseous phase has significantly more entropy than the same mass of carbon that is chemically bound in organisms and solids (e.g., in biota, coal, and carbonate rocks), trapped in sedimentary rocks (e.g., in oil and natural gas), and trapped in ice (e.g., in methane clathrates and permafrost).

The conceptual model for the HMH also considers that taxes and rewards for carbon will incentivize goods and services differently, resulting in two different patterns of decarbonization within civilization and two different patterns of energy dissipation within civilization. The conceptual model is that two market prices with opposite sign (Fig. 2) will result in two patterns of energy dissipation that can reduce the entropy of carbon in the environment. This conceptual model includes the radical 
Table 1 The Holistic Market Hypothesis (HMH) proposes two externalized costs of carbon emissions and corresponding tools, policies, and objectives

Holistic Market Hypothesis (HMH)

Social cooperation to mitigate carbon emissions is maximized with "carrot" and "stick" carbon pricing, and the economy is more resilient with a rebalancing of good efficiency with good inefficiency ${ }^{\mathrm{a}}$. Resilience emerges in a trade-off between the complementary objectives of market efficiency and long-term climate certainty

(Type I) Neoclassical perspective bon (SCC) is the time-discounted marginal impact that carbon emissions have on economic welfare. The SCC is a negative externality generated by private producers who do not pay for the spillover damages created by their carbon emissions

\section{(Type II) Biophysical perspective}

Positive Externality: The Risk Cost of Carbon (RCC) is the marginal cost of setting risk tolerances for unwanted global warming and avoiding dangerous tipping points. The RCC is the cost of implementing preventative climate insurance, and this cost is dispersed through the economy via currency trading. The preventative insurance is a positive externality because it is a 'public good' that provides longterm physical benefits that are non-rivalrous and non-excludable

\section{Tool: Carbon tax (b'stick")}

Policy: The carbon tax is a negative carbon price that is imposed on carbon emissions. Administration of the tax is relatively simple because the tax can be charged on fossil fuels as a carrier of carbon and/or at the points where carbon emissions occur. The tax is a type of fiscal policy and is managed by the government

Objective: The tax price is guided by the SCC and cost-benefit analysis for improving market efficiency (i.e., good efficiency). The objective is to maximize economic welfare
Tool: Global carbon reward and parallel currency ("carrot")

Policy: The global carbon reward is a positive carbon price that is offered for voluntary reductions in carbon emissions and carbon sequestration. The reward is delivered as a parallel currency, and the administration is relatively demanding because numerous technologies are involved and policing is needed to limit cheating. The reward is a type of monetary policy (an exchange rate mechanism) that is managed by central banks

Objective: The carbon reward price is guided by the RCC and cost-effectiveness analysis for limiting climate systemic risk with good inefficiency. The long-term objective is to achieve climate certainty

\section{Adapted from Chen et al. (2017)}

aSee Sect. 4.3 for an explanation of "good efficiency" and "good inefficiency"

bap-and-trade schemes also generate a negative price on carbon, but they use different tools and methods to the carbon tax and create a somewhat different set of outcomes in terms of costs and risks

new concept that the dominant social agreements and social responses of the Type I and Type II policies must be time-asymmetric to be consistent with the Second Law of Thermodynamics and the one-directional "arrow of time" (Sect. 1.4).

Chen et al. (2017) further claim that under the HMH "...the SCC and RCC coexist in a cost duality and without paradox" (p. 29). It is argued here that two paradoxes are inadvertently created when the Type I and Type II perspectives are assumed to be incompatible and mutually exclusive. The first paradox is the paradox of agency, which occurs when only one of the two perspectives is believed correct. The first paradox is resolved below. The second paradox is a paradox of time discounting, which is addressed in Sect. 5.1.3. 
To resolve the paradox of agency, consider that the (Type I) neoclassical and (Type II) biophysical perspectives differ significantly. The Type I perspective is anthropocentric by assuming that human agency is the primary agency in the economy. The Type II perspective is systemic by assuming that energy dissipation is the primary agency in the economy. The two perspectives appear paradoxical because they both seem plausible but can also result in radically different interpretations. Under the $\mathrm{HMH}$ this paradox is resolved by treating the paradox as a misinterpretation: the claim here is that the Type I and Type II perspectives are compatible when human agency is considered a product of energy dissipation. This interpretation of human agency implies that the biomechanics of economic agents is far too complex to be modeled deterministically and that the neoclassical approach of studying human behavior is a pragmatic simplification. Under the HMH, both types of agency-(Type I) human agency and (Type II) energy dissipation-are assumed to operate simultaneously.

The crucial difference between Type I and Type II perspectives is not their source of agency, but rather it is the manner in which these perspectives influence policy choices for managing carbon emissions. The crucial question is this: why do (Type I) neoclassical economists promote policies for a negative price on carbon instead of a positive price? Under the HMH it is posited that Type I economists-with their anthropocentric biases - instinctively seek to maximize economic welfare, and in doing so they have adopted the negative carbon price because the biophysical networks associated with taxes are most suitable for improving market efficiency. Under the $\mathrm{HMH}$ it is posited that the biophysical networks associated with the global carbon reward-a positive carbon price-are most suitable for improving climate certainty. The HMH is selfconsistent by providing a unified biophysical model for (Type I) human agency and (Type II) energy dissipation and their associated climate policies (refer Table 1).

\subsection{Risk Cost of Carbon}

According to Chen et al. (2017), the Risk Cost of Carbon (RCC) is the average market price of voluntary mitigation (USD per $\mathrm{tCO}_{2} \mathrm{e}$ ) that is sufficient to ensure that a certain level of global warming, $\Delta T$, will not be exceeded within a risk tolerance of $R(\%) . \Delta T$ is defined as a global average surface temperature change $\left({ }^{\circ} \mathrm{C}\right)$ relative to a preindustrial baseline, and $\Delta T$ and $R$ are applied over a rolling 100-year planning horizon denoted by the end-year, $Y$.

A hypothetical example of the RCC is the market price for a global carbon reward that will ensure that the change in average global surface temperature $(\Delta T)$ does not exceed $2{ }^{\circ} \mathrm{C}$ over the next 100 years, with a risk tolerance of $33 \%(R)$. Multiple risk tolerances $(\Delta T, R)$ can be defined and addressed simultaneously. For example, four possible $(\Delta T, R)$ values are $\left(1.5^{\circ} \mathrm{C}, 50 \%\right),\left(2{ }^{\circ} \mathrm{C}, 33 \%\right),\left(3{ }^{\circ} \mathrm{C}, 15 \%\right)$, and $\left(4{ }^{\circ} \mathrm{C}, 3 \%\right)$. Actual risk tolerances should be decided in an international forum.

The total cost of carbon (TCC) is a notional measure of the total externalized cost of carbon emissions, and it is defined as the sum of the SCC and RCC over time, as follows: 


$$
\operatorname{TCC}_{i}(t)=\operatorname{SCC}(t)+\operatorname{RCC}_{i}(t)
$$

where $t$ denotes time in calendar years and subscript $i$ denotes the year of the most recent risk assessment. An alternative to using Eq. (3) is to represent TCC as a two-dimensional vector in a phase space, with the dimensions being the negative externality (SCC) and the positive externality (RCC). The SCC and RCC can have statistical correlation since both values will tend to increase with additional carbon emissions.

The purpose of the rolling 100-year time horizon is to anticipate and avoid unwanted global warming, and it takes into consideration the time lag of warming and the imperfect ability of actors to maintain their service agreements. The 100-year horizon is needed to establish a trade-off between short-term market efficiency and long-term climate certainty (Table 1). The 100-year time horizon is based on findings that (a) $60 \%$ of the equilibration surface temperature response occurs $25-50$ years after $\mathrm{CO}_{2}$ emissions (Hansen et al. 2013) and (b) most of the atmospheric $\mathrm{CO}_{2}$ concentration adjustment occurs 100 years after $\mathrm{CO}_{2}$ emissions (IPCC 2013). The 100-year time horizon also corresponds to the time standard for the Global Warming Potential (GWP) of greenhouse gases (IPCC 2014c). The application of 100-year agreements has a legal precedent with 99-year leases on property under common law. For example, real estate in the Australian Capital Territory is managed on 99 -year leases. ${ }^{2}$

\title{
2.2 Market Policy Dualism
}

The HMH rests on a proposed market principle, called Market Policy Dualism (MPD), which is inspired by the "carrot and stick" metaphor of combining rewards and penalties to improve social cooperation. Chen et al. (2017) propose Market Policy Dualism (MPD) as follows:

\begin{abstract}
MPD is a principle that pairs of market policies for environmental mitigation are available based on relationships that are complementary-and-opposite. MPD also includes an implicit assumption that a complementary pair of market-based policies offers benefits, such as rebalancing of social relationships for social feedbacks (e.g., new group dynamics) and policy synergies (e.g., aggregation of price signals). (p. 12)
\end{abstract}

Evidence that supports MPD is found in a handful of social science experiments (e.g., Andreoni et al. 2003; Hilbe and Sigmund 2010; Chen et al. 2015). Chen et al. (2015) undertook a study of positive and negative incentives based on a public goods game. They found that "...punishment acts as a 'booster stage' that capitalizes on and amplifies the pro-social effects of rewarding..." and that the hybridization of incentives provides ". . . a surprisingly inexpensive and widely applicable method of promoting cooperation" (p. 1). Andreoni et al. (2003) undertook a study of "carrot and stick" incentives based on a proposer-responder game. They discovered that:

\footnotetext{
${ }^{2}$ Taylor, G., 2016. Can people own land in the ACT? ABC News. 4 July 2016.
} 
Thus, while adding rewards only had little effect, adding rewards to punishments has a profound effect. In other words, rewards and punishments seem to act as complements in encouraging proposers to increase their offers. (p. 897)

Andreoni et al. (2003) conclude that (a) rewards alone are relatively ineffective, (b) punishments improve cooperation by eliminating extreme selfishness, and (c) combining rewards and punishments has a "very strong effect" because rewards and punishments can act to complement one another. It also appears that penalties and rewards "... are not merely substitutes in enforcing a fixed objective, but rather that their availability alters the ideals that they enforce" (p. 901). The literature on "carrot and stick" incentives provides solid support for MPD; however a statisticalmechanical model that explains the biophysics of MPD is currently lacking.

\subsection{Epistemology of Complementary Relationships}

An epistemology is a method or tool that supports the justification of a belief, as opposed to relying on opinions. In this exposition we clarify the epistemology of Chen et al. (2017), which is the epistemology of complementary-and-opposite relationships. The authors define the epistemology as follows:

The application of MPD begins with the epistemology of defining complementary pairs as two socio-economic relationships that have opposite characteristics and a capacity to aggregate price signals. (p. 12)

The epistemology begins with (Type I) negative pricing and (Type II) positive pricing (refer Table 1). The Type I and Type II policies provide incentives to reduce carbon emissions, but their effects in the marketplace differ because they price carbon in complementary and opposite ways. The epistemology transcends neoclassical economics by considering climate policies as biophysical networks that are designed to reduce the entropy of carbon in the environment (refer Sects. 1.4 and 1.6).

Before attempting to verify the HMH with the epistemology, it is necessary to review the policy for a global carbon reward, including its framework, economic instrument, financial mechanism, and the risk assessment approach for estimating the RCC (see Sect. 3).

\section{Global Carbon Reward}

\subsection{Policy Background}

The Holistic Market Hypothesis (HMH) is a market theory that the global carbon reward is inherently suited to the objective of internalizing the Risk Cost of Carbon (RCC) into the economy (Type II in Table 1). Chen et al. (2017) recommend that the global carbon reward be implemented using their Global 4C Risk Mitigation policy, which is abbreviated as "Global 4C." Under the Global 4C policy, a parallel 
currency - which is the reward instrument-is used to internalize the RCC into the economy. The parallel currency is given the generic name Complementary Currencies for Climate Change (4C). The Global 4C policy is described below with caveats that the policy has not been validated with models or pilots and the policy may need some adjusting or refining.

\subsection{Policy Framework}

The Global 4C policy is designed to offer a global carbon reward (Type II in Table 1), whereby the reward payment will be provided with $4 \mathrm{C}$ issuance. The reward's financial value will equal the current exchange rate of $4 \mathrm{C}$, and the wealth transferred to market actors is the seigniorage income of the $4 \mathrm{C}$ as it is issued. The seigniorage income will equal the $4 \mathrm{C}$ exchange rate (USD per $100 \mathrm{~kg}$ of $\mathrm{CO}_{2} \mathrm{e}$ ) multiplied by the mass of $\mathrm{CO}_{2} \mathrm{e}$ mitigated and less administrative costs that will be deducted as commissions. The Global $4 \mathrm{C}$ policy will achieve its macroeconomic objectives by pegging the $4 \mathrm{C}$ price to mirror the $\mathrm{RCC}$ over time.

The global carbon reward-provided by the 4C parallel currency-will be offered to market actors who voluntarily mitigate carbon, and a wide spectrum of mitigation technologies will be rewarded. The rewards may be weighted to reflect social and ecological co-benefits, and the reward rules will have a scientific basis. The amount of $4 \mathrm{C}$ issued will be linked to measurement reporting and verification (MRV) for accountability, and the $4 \mathrm{C}$ will be offered conditionally such that actors are required to fulfill service agreements that could last for up to 100 years. Chen (2018a, b) elaborates on how long-lived service agreements can be managed with blockchain ledgers and "smart" digital contracts. A central authority will govern the MRV, but operationally there will be numerous contractors working over the Internet to undertake the MRV. Market actors can be supported with secondary services for information sharing, collaboration, and coinvesting in projects.

Central banks will play a major role in the Global 4C policy, as they will be required to implement unorthodox monetary policies involving quantitative easing (QE) and currency trading - called carbon quantitative easing (CQE) - to peg the 4C price to the RCC over the rolling 100-year planning horizon. As is explained in Sect. 3.4, by pegging the $4 \mathrm{C}$ price to mirror the RCC, a secular "bull market" in $4 \mathrm{C}$ will be invoked in foreign exchange currency markets (the Forex) for the time when the $\mathrm{RCC}$ is rising in magnitude. The $4 \mathrm{C}$ bull market will attract private purchases of $4 \mathrm{C}$, thereby mobilizing private finance for a high-inertia low-carbon transition.

To maintain public accountability, the total supply of $4 \mathrm{C}$ will be maintained in proportion to a global carbon stocktake. The central authority will provide accountability by periodically reconciling defaults on service agreements with 4C chargebacks and $4 \mathrm{C}$ demurrage fees. Demurrage fees are equivalent to a negative interest rate charged on $4 \mathrm{C}$ holdings. The carbon recorded in the stocktake will not be available for trading as carbon offset credits (although $4 \mathrm{C}$ will be available for 
trading); and the retirement of all of the carbon that is recorded in the stocktake will make carbon offsets scarcer and more expensive.

The Global 4C policy will internalize the RCC into the world economy. This internalization process may be described as a deleveraging process for climate risk. The deleveraging of risk will occur as $4 \mathrm{C}$ liquidity is provided to low-carbon projects in proportion to their carbon mitigation results. The improved profitability of low-carbon projects will attract private investment to the low-carbon sector of the economy, and it will leverage debt finance for low-carbon projects. Climate risk deleveraging will also occur when market actors respond to the $4 \mathrm{C}$ global reward by undertaking long-term R\&D programs to develop carbon dioxide removal (CDR) technologies that are scalable and profitable.

\subsection{Parallel Currency}

As mentioned above, the economic instrument of the Global $4 \mathrm{C}$ policy is a parallel currency, called 4C. A justification for adopting a parallel currency is based on the epistemology presented in Sect. 4 and the macroeconomic benefits described in Sect. 5. The chosen unit of account for $4 \mathrm{C}$ is smaller than that of the RCC by a factor of 10 . The $4 \mathrm{C}$ is denominated in $100 \mathrm{~kg}$ lots of $\mathrm{CO}_{2} \mathrm{e}$ mitigated, whereas the RCC has units of USD per $1000 \mathrm{~kg}$ of $\mathrm{CO}_{2} \mathrm{e}$ mitigated. A smaller mass was adopted for the $4 \mathrm{C}$ unit of account to provide a more convenient exchange rate. The $4 \mathrm{C}$ exchange rate and carbon reward price is defined as follows:

$$
4 \mathrm{C}(t) \cong 0.10 \times \mathrm{RCC}(t)
$$

The 4C currency will be a stateless international currency suitable for trading with national currencies in the Forex. Holders of $4 \mathrm{C}$ will be subject to domestic laws regarding taxation, peer-to-peer currency trading, banking, and general trade. From an administrative perspective, 4C is a central bank digital currency (CBDC) and may be developed using distributed ledger technologies. Special administrative permissions are given to a peak authority for managing the CBDC ledger so that the authority can maintain proportionality between the $4 \mathrm{C}$ supply and the carbon stocktake.

Private holders of the 4C parallel currency may trade their 4C holdings with other market actors, and they may exchange their $4 \mathrm{C}$ for national currencies, but no amount of carbon will change hands when $4 \mathrm{C}$ is traded. This is because the carbon is automatically "retired" and holders of 4C are not granted ownership to the underlying carbon stock. Holders of $4 \mathrm{C}$ are only granted ownership of the financial value provided by $4 \mathrm{C}$, and this value is underwritten by central banks. Although $4 \mathrm{C}$ is tradable it cannot be used to offset pollution, and with sweet irony $4 \mathrm{C}$ will have tangible value because it will help avoid dangerous-to-catastrophic climate change while supporting social and ecological co-benefits. 


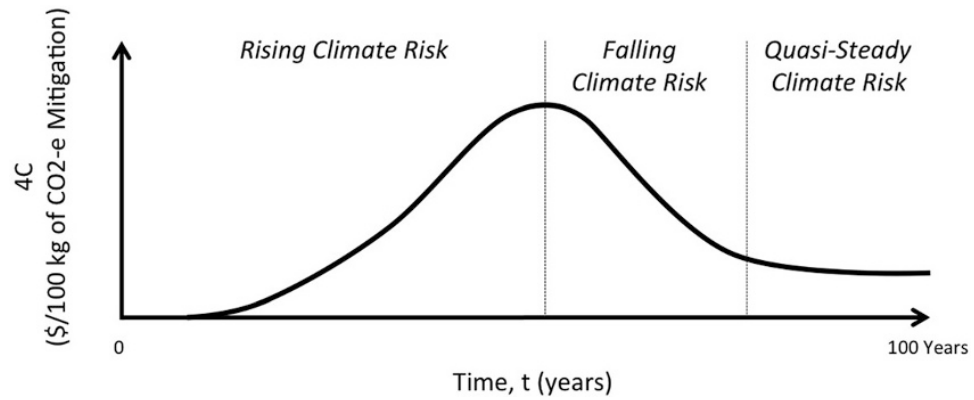

Fig. 3 A hypothetical example of the "100-year advance 4C price alert" that advertises the global carbon reward for climate mitigation. The $4 \mathrm{C}$ price mirrors the Risk Cost of Carbon (RCC), and it communicates the level of risk to financial markets (adapted from Chen et al. 2017)

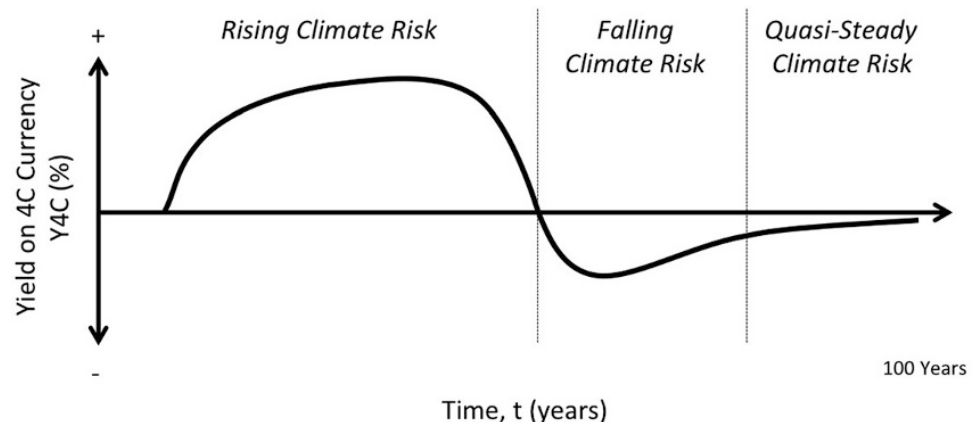

Fig. 4 A hypothetical example of the yield on 4C holdings based on the "100-year advance 4C price alert" shown in Fig. 3. Periods of positive yield represent an opportunity for a risk-free return on $4 \mathrm{C}$ holdings, and this is how climate risk is priced into the global financial system

\subsection{Financial Mechanism}

The financial mechanism of the Global $4 \mathrm{C}$ policy is a currency exchange rate mechanism. This mechanism, with its social agreements, may be called the Carbon Exchange Standard (CES). The focal point of the CES is the "100-year advance 4C price alert" (see Figs. 3 and 4), which may be described as the $4 \mathrm{C}$ floor price. A peak authority will be responsible for administering the CES and guiding central banks when trading $4 \mathrm{C}$ so that the $4 \mathrm{C}$ floor price is upheld. The $4 \mathrm{C}$ price alerts will be published on an annual basis shortly after the annual risk assessments for the RCC are completed, as described in Sect. 3.5.

The "100-year advance $4 \mathrm{C}$ price alert" will incentivize private demand for $4 \mathrm{C}$ based on the anticipated yield on $4 \mathrm{C}-\mathrm{Y} 4 \mathrm{C}(t)$ - which can be estimated from the annual change in the RCC, as follows: 


$$
\mathrm{Y} 4 \mathrm{C}(t) \cong 100 \% \frac{\mathrm{RCC}_{i}(t+1)-\mathrm{RCC}_{i}(t)}{\mathrm{RCC}_{i}(t)}
$$

A positive yield on $4 \mathrm{C}$ will generate a multi-decade bull market in $4 \mathrm{C}$ trading (i.e. promoting $4 \mathrm{C}$ saving), and conversely a negative yield will generate a multidecade bear market in $4 \mathrm{C}$ trading (i.e. promoting $4 \mathrm{C}$ spending). This exchange rate mechanism has legitimacy based on the estimated RCC. Given that the Forex has high liquidity - with daily currency trading of roughly USD 3 trillion on average ${ }^{3}$ - it is assumed that the RCC can be internalized into the global financial system via the Forex. Central banks will act as the "buyers of last resort" whenever private demand for $4 \mathrm{C}$ is insufficient to maintain the $4 \mathrm{C}$ floor price in the Forex. Central banks will retain their $4 \mathrm{C}$ purchases in holding accounts, thereby ensuring that the $4 \mathrm{C}$ has the status of both a hard currency and a financial security.

A central authority for the CES will coordinate central bank trading of $4 \mathrm{C}$ to target the floor price (refer Eq. 4) and to apportion the financial contributions of each national economy to achieve a uniform marginal change in the exchange rate of each national fiat currency. This will spread the cost of the $4 \mathrm{C}$ stimulus as uniform monetary inflation-ceteris paribus. Central banks will employ strategic quantitative easing $(\mathrm{QE})$ - called carbon quantitative easing $(\mathrm{CQE})$ — and currency trading in open markets to negate the need for taxes to fund the policy for a global carbon reward.

The "100-year advance 4C price alert" (see Figs. 3 and 4) simultaneously communicates three important messages: (1) the global reward for mitigating carbon emissions, (2) the 4C investment opportunity with a risk-free yield (e.g., a U.S. treasury bill is considered risk-free), and (3) the long-term climate risk. Over the long run, a period of quasi-steady RCC values and $4 \mathrm{C}$ exchange rates may emerge, as suggested in Figs. 3 and 4. A future period of long-term quasi-steady risk is anticipated because there will likely be a long-term need for negative emissions technologies (NETs) to counter residual carbon emissions and to restore the climate with carbon drawdown. The feasibility of NETs is currently uncertain (Fuss et al. 2014; Gasser et al. 2015); however the "100-year advance 4C price alert" will incentivize R\&D for new and more effective NETs.

\subsection{Risk Assessments}

The global carbon reward requires that annual risk assessments be undertaken to quantify the Risk Cost of Carbon (RCC) (refer Sect. 2.1). The RCC should be based on a set of average global temperature rises, $\Delta T_{j}$, that could occur during the rolling 100 -year time horizon as a result of climate sensitivity to anthropogenic GHG emission and possible tipping points (e.g., Lenton 2012). Before the assessments can be undertaken, a political decision is needed to define the risk tolerance, $R_{j}$, for

\footnotetext{
${ }^{3}$ Reuters (March 13, 2017). "Daily FX trade more like $\$ 3$ trillion than 5: CLS” by Patrick Graham.
} 
each $\Delta T_{j}$ value of concern. For example, $(\Delta T, R)$ could be set equal to $\left(2{ }^{\circ} \mathrm{C}, 33 \%\right)$ over the rolling 100-year time horizon.

The RCC assessments involve three major steps:

(Step 1) Estimating the Systemic Risk of a Climate Mitigation Failure (SRCMF)

(Step 2) Estimating the target mitigation rate, $\Delta Q(t)$, from the SRCMF

(Step 3) Estimating the Risk Cost of Carbon (RCC) from the $\Delta Q(t)$

Step 1 is a risk assessment for estimating the $\operatorname{SRCMF}\left\{\Delta T_{j}, Y\right\}$ for each $\Delta T_{j}$ value of concern and over the rolling 100-year planning horizon, denoted by calendar year Y. This should take into consideration the social, political, financial, and biophysical factors that are driving carbon emissions and causing global warming. The SRCMF $\left\{\Delta T_{j}, Y\right\}$ assessments should use adaptable methods that take into consideration quantitative and qualitative knowledge (e.g., Shapiro and Koissi 2015).

Step 2 is a risk assessment for estimating a single target carbon mitigation rate, $\Delta Q(t)$, that can reduce each value of $\operatorname{SRCMF}\left\{\Delta T_{j}, Y\right\}$ to below its respective $R_{j}$ tolerance. A formula that summarizes Steps 1 and 2 is as follows:

$$
\Delta Q_{i}(t)=\text { Function }\left\{\operatorname{SRCMF}\left\{\Delta T_{j}, Y_{i}\right\}, R_{j}: j=1, N\right\}
$$

where Function $=$ risk assessment; $R=$ adopted risk tolerance $(\%)$, SRCMF $=$ Systemic Risk of a Climate Mitigation Failure (\%); $N=$ total number of risk limits (integer); $Y=$ last calendar year of the rolling 100-year planning horizon (year); $\Delta Q=$ target mitigation rate ( $\mathrm{CO}_{2} \mathrm{e}$ per year); $\Delta T=$ global average surface temperature anomaly above a baseline $\left({ }^{\circ} \mathrm{C}\right) ; j=$ subscript denoting the $j$ th risk limit that is considered concurrently (integer); $i=$ subscript denoting the $i$ th risk assessment (integer); and $t=$ time (year).

Step 3 is a cost-effectiveness analysis that estimates the $\operatorname{RCC}(t)$ from $\Delta Q(t)$. This analysis requires the estimation of a Systemic Risk Abatement Cost Curve (SRACC) for international markets. The SRACC presents the average cost of abating and sequestering carbon within the context of available technologies and the market's actual capacity and willingness to participate. The SRACC takes into consideration the opportunity costs and the various hidden costs, including the costs of administration, policing, long-term monitoring, free riding, and defaulting. A formula that summarizes Step 3 is presented as follows:

$$
\operatorname{RCC}_{i}(t)=\operatorname{SRACC}_{i}\{\Delta Q, t\}
$$

where $\mathrm{RCC}=$ Risk Cost of Carbon (USD per $\mathrm{t} \mathrm{CO}_{2} \mathrm{e}$ mitigation service); SRACC $=$ Systemic Risk Abatement Cost Curve; $\Delta Q=$ target mitigation rate ( $\mathrm{CO}_{2}$ e per year); $i=$ subscript denoting the $i$ th risk assessment (integer); and $t=$ time (year). 


\section{Analytical Verification}

\subsection{Premise}

The Holistic Market Hypothesis (HMH) of Chen et al. (2017) is a hypothesis that the inherent utility of a global carbon reward is to internalize the Risk Cost of Carbon (RCC) into the economy for the objective of limiting climate risk (refer Table 1). A premise of this hypothesis is that market inefficiencies are acceptable as a trade-off for reducing climate systemic risk and avoiding dangerous tipping points. Two key premises are involved in the HMH: (a) market-based climate policies function as biophyiscal networks that dissipate energy and reduce the entropy of carbon in the environment while increasing total entropy, and (b) market-based climate policies that employ positive and negative carbon pricing are time-asymmetric under the Second Law of Thermodynamics. The HMH is verfied by checking for timeasymmetry of the dominant social relationships and dominant social responses of the complementary policies. Market Policy Dualism (MPD) is the inspiration for the epistemology of complementary policy relationships, which is explained in Sect. 4.2. The epistemology is applied in three steps: (Step 1) reversing prices, (Step 2) declaring a currency with biophysical units, and (Step 3) comparing policy objectives based on the "arrow of time." The logic of the three steps is explained below, and the arrow of time refers to monotonic entropy increases under the Second Law (Sect. 1.4). The premise also includes the following five axiomatic statements, which are explained in Sect. 4.3:

Axiom A: Goods and services have embodied energy.

Axiom B: The unit type (unit of account) of money sets a context for the store of value.

Axiom C: Carbon taxes can be used to improve the efficiency of markets.

Axiom D: Actors make risk-reward trade-offs when investing.

Axiom E: Market-based policies that aim to reduce carbon emissions can do so by selectively increasing market efficiencies and by selectively increasing market inefficiencies.

\subsection{Epistemological Translation}

The HMH involves a three-step epistemological translation of market policies. The translation is used to derive the policy for a positive carbon price from a policy for a negative carbon price. Perhaps surprising is that market policies have the same dimensionality as money, and this is because they have similar functions (see Table 2). William Jevons (1875) famously defined money as having four functions, and his ideas inspired Milnes (1919) to write the following couplet: "Money's a matter of functions four, a Medium, a Measure, a Standard, a Store" (p. 55). The functions of market policies and money are similar, but only certain types of market policy require a new currency instrument. The global carbon reward is one such 
Table 2 The three-step epistemological translation for carbon pricing is compared with the four functions of money to achieve dimensional completeness

\begin{tabular}{|c|c|c|c|c|c|c|}
\hline \multicolumn{4}{|c|}{ Carbon pricing } & \multicolumn{3}{|l|}{ Money } \\
\hline Translation $^{\mathrm{a}}$ & Carbon tax ${ }^{\mathrm{b}}$ & $\begin{array}{l}\text { Carbon } \\
\text { subsidy }\end{array}$ & $\begin{array}{l}\text { Carbon } \\
\text { reward }^{\mathrm{c}}\end{array}$ & $\begin{array}{l}\text { Jevons } \\
(1875)\end{array}$ & Classical & Biophysical \\
\hline $\begin{array}{l}\text { Step } \\
\text { 2. Currency }\end{array}$ & $\begin{array}{l}\text { National fiat } \\
\text { currency }\end{array}$ & $\begin{array}{l}\text { National } \\
\text { fiat } \\
\text { currency }\end{array}$ & $\begin{array}{l}\text { Parallel } \\
\text { currency }\end{array}$ & Medium & $\begin{array}{l}\text { Medium } \\
\text { of } \\
\text { exchange }\end{array}$ & $\begin{array}{l}\text { Medium of } \\
\text { exchange }\end{array}$ \\
\hline $\begin{array}{l}\text { Step } \\
\text { 2. Units }\end{array}$ & USD & USD & $\begin{array}{l}100 \mathrm{~kg} \text { of } \\
\mathrm{CO}_{2} \mathrm{e} \\
\text { mitigation }\end{array}$ & Measure & $\begin{array}{l}\text { Unit of } \\
\text { account }\end{array}$ & $\begin{array}{l}\text { Unit of } \\
\text { account }\end{array}$ \\
\hline $\begin{array}{l}\text { Step } \\
\text { 3. Arrow of } \\
\text { time }\end{array}$ & $\begin{array}{l}\text { Policy of } \\
\text { improving } \\
\text { market effi- } \\
\text { ciency using } \\
\text { carbon taxes } \\
\text { guided by the } \\
\text { SCC }\end{array}$ & $\begin{array}{l}\text { Policy of } \\
\text { reducing } \\
\text { carbon } \\
\text { emissions }\end{array}$ & $\begin{array}{l}\text { Policy of lim- } \\
\text { iting systemic } \\
\text { risk with car- } \\
\text { bon rewards } \\
\text { guided by the } \\
\text { RCC }\end{array}$ & Standard & $\begin{array}{l}\text { Social } \\
\text { agreement }\end{array}$ & $\begin{array}{l}\text { Entropic } \\
\text { relationship }\end{array}$ \\
\hline $\begin{array}{l}\text { Step } \\
\text { 1. Price } \\
\text { reversal }\end{array}$ & $\begin{array}{l}\text { Negative price } \\
\text { (USD per } \\
\mathrm{t} \mathrm{CO}_{2} \mathrm{e} \\
\text { pollution) }\end{array}$ & $\begin{array}{l}\text { Positive } \\
\text { price } \\
\text { (USD per } \mathrm{t} \\
\mathrm{CO}_{2} \mathrm{e} \\
\text { mitigation) }\end{array}$ & $\begin{array}{l}\text { Positive price } \\
\text { (USD per } \mathrm{t} \\
\mathrm{CO}_{2} \mathrm{e} \\
\text { mitigation) }\end{array}$ & Store & $\begin{array}{l}\text { Store of } \\
\text { value }\end{array}$ & Power $(\mathrm{J} / \mathrm{s})^{\mathrm{d}}$ \\
\hline
\end{tabular}

${ }^{\mathrm{a}}$ See Sects. 4.4, 4.5, and 4.6 for the epistemological translations

${ }^{\mathrm{b}}$ Carbon taxes have a negative store of value and are not themselves a currency

${ }^{\mathrm{c}}$ The results of the epistemological translation, after Chen et al. (2017)

${ }^{\mathrm{d}}$ Garrett (2012); see Eq. (2)

policy, because it declares a parallel currency denominated in carbon. Cap-and-trade schemes declare permits and carbon offset credits for trading in carbon markets, but these are not currencies per se because their social agreements are only designed to address specific markets.

Jevons (1875) discussed the "standard of value" of money in terms of borrowing and lending, but in recent years the term has been replaced with "social agreement," which is a more general description of this function (see Table 2). For example, Eisenstein (2011) writes: "Money is merely a social agreement, a story that assigns meanings and roles" (p. 108).

Table 2 compares Jevons (1875) four functions with a classic description and a biophysical interpretation of these same functions. The "store of value" corresponds to power $(\mathrm{J} / \mathrm{s})$ under the biophysical description of money, which is inspired by Garrett's (2012) economic model [refer Eqs. (1) and (2)]. The "social agreement" corresponds to the biophysical function called the "entropic relationship," which is introduced here with Table 2. This biophysical interpretation of the social agreement refers to the influence that social agreements have on future patterns of production, consumption, energy dissipation, and high-entropy waste, such as $\mathrm{CO}_{2}$ emissions. In Sect. 1.6 it was suggested that market-based climate policies are biophysical networks through which energy dissipation can reduce the entropy of carbon. Step 3 of the translation is the reversal of the social agreement for the carbon tax to achieve a 
policy objective for the carbon reward: to be consistent with the "arrow of time" under the Second Law (see Table 2).

\subsection{Axioms}

Axiom A is a statement that goods and services contain "embodied" energy because energy is always needed to produce goods and services. A corollary to Axiom A is that money is indirectly associated with embodied energy, because the value of money grants access to goods and services.

Axiom B is a statement that the unit type (unit of account) of money is fundamentally important for setting the context of value in the economy. The unit type of money must be an extensive property, and in the economy there are three principal options: (1) commodities (e.g., 1 oz. of silver), (2) socially or legally declared information (e.g., USD), and (3) services (e.g., 1 hour of education). A fourth option is to adopt a basket of units, but this is not a principal unit type.

A corollary to Axiom B is that service money-money with units defined by a service-is useful for offering rewards to incentivize positive externalities. The corollary is that monetary policy can be used to incentivize the supply of services, assuming that an administrative system is available to couple the currency supply to the observed supply of service. An example is Solarcoin, ${ }^{4}$ which is a cryptographic token and reward with units of $1 \mathrm{MWh}$ of solar-derived electricity.

Axiom $\mathbf{C}$ refers to an 0established principle in economics that when a carbon tax (a Pigovian tax) is guided by cost-benefit analysis, the tax improves the efficiency of the market by increasing the marginal private cost of production so that the carbon emissions are reduced sufficiently to achieve a social welfare optimum. The optimum in consumption occurs when the marginal social cost equals the marginal social benefit. This kind of efficiency is neoclassical and is described here as "good efficiency."

Axiom D refers to an established principle in economics that when market actors make investments with imperfect knowledge, they invest according to a risk-versusreward trade-off (or risk-return trade-off). Consequently, market actors take greater risks when they anticipate greater rewards/returns.

Axiom $\mathbf{E}$ is a statement that there exist two ethics for reducing carbon emissions. One ethic is to create (a) good efficiency (refer Axiom C), and the other ethic is to create (b) good inefficiency. The term "good efficiency" is introduced to describe the neoclassical ambition of improving market efficiency to maximize social welfare: the point where the private cost of production plus externalities equals the social benefit. The term "good inefficiency" is introduced to describe the diversion of capital and resources to reduce carbon emissions for the objective of limiting systemic risk and providing climate certainty. This "good inefficiency" is the result of a tradeoff between market efficiency and climate certainty, and it may result in an

${ }^{4}$ https://solarcoin.org 


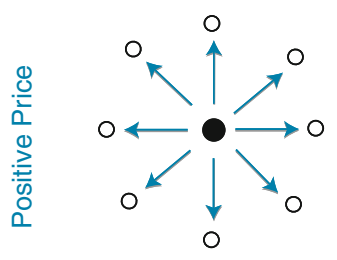

LEGEND FOR THE CARBON SUBSIDY

(Step 1) Price Reversal

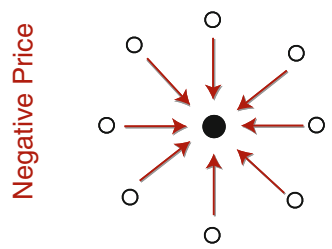

LEGEND FOR THE CARBON TAX
$\pi$ Tax Payment
Authority
O Market Actor (Polluter)

Fig. 5 Climate policies represented as network diagrams: (bottom) the carbon tax and a negative price on carbon emissions and (top) the carbon subsidy and a positive price on carbon mitigation. The horizontal dotted-dashed line denotes the translation for price reversal

increase in other measures of well-being that take into account socio-ecological regeneration and sustainability.

\subsection{Translation for Price Reversal (Step 1)}

The first epistemological translation compares a negative carbon price with a positive carbon price, as illustrated in Fig. 5. The dotted-dashed horizontal line in Fig. 5 denotes this translation. The translation compares a tax for carbon emissions with a generic subsidy for carbon mitigation. The translation identifies complementary-and-opposite pricing and financial flows. The carbon tax and the carbon subsidy are complementary because they both incentivize a reduction in carbon emissions. Tax payments (USD) denoted in Fig. 5 are calculated from the negative price (USD per tonne of $\mathrm{CO}_{2} \mathrm{e}$ emissions) multiplied by the mass of carbon emitted, whereas subsidy payments (USD) are calculated from the positive price (USD per tonne of $\mathrm{CO}_{2} \mathrm{e}$ mitigation) multiplied by the mass of avoided/sequestered emissions. The avoided emissions are calculated as the difference between a theoretical baseline of emissions (i.e., a rule-based measure of emissions for a single market actor or for an entire market) and the actual carbon emissions over time. In both policies a national fiat currency is used as the medium of exchange for financial payments. 


\subsection{Translation for Currency Units (Step 2)}

The term "fiat" refers to any currency with units that are legally declared-ex nihilo - and every national currency in use today is a fiat currency (e.g., USD, EUR, YEN, GBP, CNY, etc.). The carbon tax and the carbon subsidy are paid with a national fiat currency (refer Fig. 5). The second epistemological translation takes the units of the mitigation subsidy — which are biophysical units — and uses it to declare a parallel currency. These units are " $100 \mathrm{~kg}$ of $\mathrm{CO}_{2} \mathrm{e}$ mitigated," and they become the units of the new currency, which is to be used in parallel with national fiat currencies.

The financial mechanism of the parallel currency was described in Sect. 3, and the currency is given the generic name: Complementary Currencies for Climate Change (4C). The units of $4 \mathrm{C}$ (i.e., $100 \mathrm{~kg}$ of $\mathrm{CO}_{2} \mathrm{e}$ mitigated) are smaller than the $\mathrm{RCC}$ units by one order of magnitude as a convenience. By issuing $4 \mathrm{C}$ as incentive payments, the policy is termed a "carbon reward," as distinct from the "carbon subsidy" prior to the translation. The vertical dashed line in Fig. 6 denotes the translation.

Introducing $4 \mathrm{C}$ has novel economic implications by creating a new biophysical context for money (Axiom B). Markets and institutions for the parallel currency are represented symbolically in Fig. 6, and these include (a) the mitigation market where actors receive the parallel currency as a reward for mitigating carbon emissions,

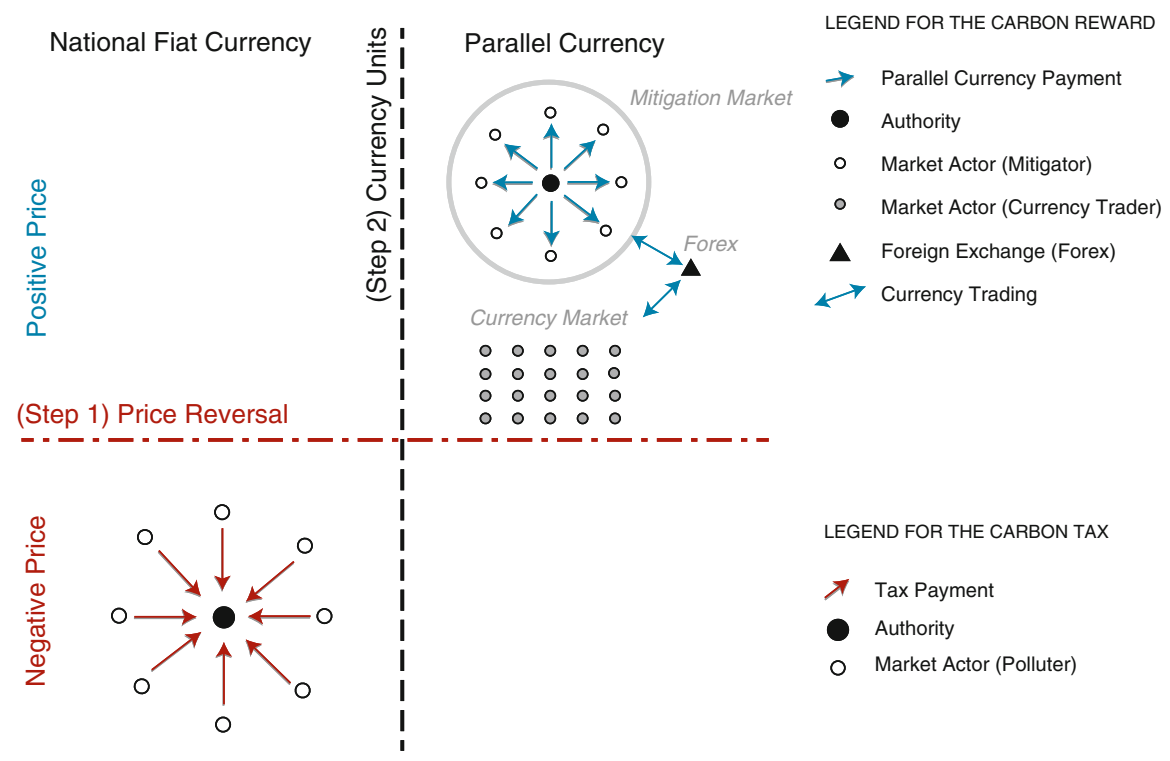

Fig. 6 Climate policies represented as network diagrams: (bottom left) the carbon tax with a negative price on carbon emissions and (right top) the global carbon reward with a positive carbon price on carbon mitigation and using a parallel currency that is traded in the Forex. The vertical dashed line denotes the translation for currency units 
(b) the currency market where actors can trade currencies, and (c) the foreign exchange for currencies (Forex) where currency trading is recorded on a ledger.

By trading the $4 \mathrm{C}$ parallel currency in the Forex, 4C becomes available in all national economies, thereby establishing $4 \mathrm{C}$ as a "global carbon reward." $4 \mathrm{C}$ needs to be managed with an official exchange rate mechanism otherwise the price of $4 \mathrm{C}$ will likely be too low and volatile. The exchange rate mechanism for $4 \mathrm{C}$ is related to the policy's objective or social agreement, and this topic is addressed with the third translation.

\subsection{Translation for the Arrow of Time (Step 3)}

The third epistemological translation makes a comparison of temporal relationships for negative and positive carbon pricing. The epistemology is used to determine if these policies are complementary-and-opposite based on the "arrow of time." The arrow of time, or time-asymmetry, is coupled to entropy change (refer Law 2 in Sect. 1.4). In this third epistemological translation, there is an expectation that negative and positive carbon pricing will both reduce/limit the mass of carbon entering the atmosphere and consequently both policies should also reduce/limit the entropy of carbon in the environment. The translation involves an a priori assumption that the

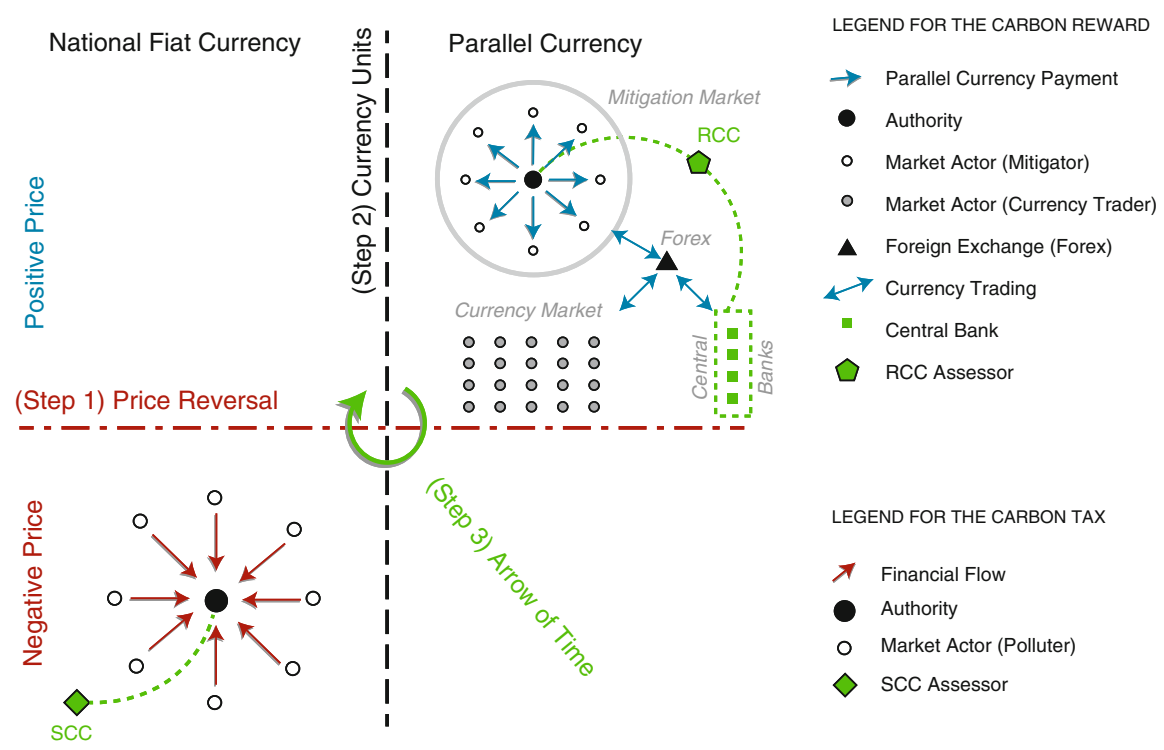

Fig. 7 Climate policies represented as network diagrams: (bottom left) the carbon tax and objectives set by the Social Cost of Carbon (SCC) and (right top) the global carbon reward and objectives set by the Risk Cost of Carbon (RCC). The reward is issued as a parallel currency and managed with an exchange rate mechanism. The circular arrow denotes the translation for the "arrow of time" 
global carbon reward can internalize the Risk Cost of Carbon (RCC) (Eqs. 6 and 7). The epistemological translation is a check on this assumption, and the appearance of time-asymmetry in the resulting economic relationships is the anticipated result that will support the hypothesis that the RCC is the second externalized cost of carbon emissions.

The third translation is symbolized in Fig. 7 as a green circular arrow to remind us that time only moves forward with entropic change. The other symbols in Fig. 7 denote the financial mechanisms and social agreements, as explained in the figure's legends. An authority is needed to set the price of the carbon tax to approximate the SCC, thereby setting the objective of the tax policy (bottom left Fig. 7). The a priori assumption is that an authority is needed to set the price of the global carbon reward to approximate the RCC, thereby setting the objective of the reward policy (top right Fig. 7). RCC values are communicated to central banks that are responsible for ensuring that the exchange rate of the parallel currency (4C) matches the RCC over time (refer Figs. 3 and 7, Sect. 3.4). The exchange rate mechanism and the 4C floor price (refer Fig. 3) are major components of the policy's social agreement, which is the "entropic relationship" of the policy (refer Table 2).

To complete the third translation, the following four time-dependent relationships for negative and positive carbon pricing are described: (1) the top-down objective of the carbon tax, (2) the top-down objective of the carbon reward, (3) the bottom-up response to the carbon tax, and (4) the bottom-up response to the carbon reward.

Based on the standard model for the SCC, the top-down objective of the carbon tax is as follows (refer bottom left of Fig. 7 and Axioms $\mathrm{C}$ and $\mathrm{E}$ ):

Relationship 1 A central authority assesses the Social Cost of Carbon (SCC) and responds by imposing a carbon tax that is guided by cost-benefit analysis: to internalize the SCC into the economy and reduce carbon emissions. The objective is to improve market efficiency, which is described here as "good efficiency."

Based on risk assessments for the RCC (Sect. 3.5), the top-down objective for the carbon reward is as follows (refer top right of Fig. 7):

Relationship 2 A central authority assesses the Risk Cost of Carbon (RCC) and responds by offering a global carbon reward (via a parallel currency) that is guided by cost-effectiveness analysis: to internalize the RCC into the economy and reduce carbon emissions. The objective is to reduce "climate systemic risk" and achieve "climate certainty."

Based on the standard model for the SCC, the bottom-up ${ }^{5}$ risk-response of market actors under the carbon tax is as follows (refer bottom left of Fig. 7 and Axiom D):

Relationship 3 Market actors operating under the carbon tax can perceive opportunities for consumption and investment, and their response will be to take risks in a risk-reward trade-off. Their decisions will be individualistic, and they may respond

\footnotetext{
${ }^{5}$ The bottom-up responses of market actors may also be called micro-foundational responses.
} 
to the carbon tax by reducing their consumption and production of carbon-intensive goods and services. The aggregate of their responses will improve market efficiency_ " good efficency"- but these actions may bear little or no relationship to the "climate systemic risk."

Based on setting the $4 \mathrm{C}$ exchange rate to mirror the RCC (Eqs. 4 and 5), the bottom-up risk-response of market actors will be as follows (refer top right of Fig. 7 and Axioms $\mathrm{C}$ and $\mathrm{E}$ ):

Relationship 4 Market actors operating under the carbon reward can perceive opportunities for consumption and investment, and their response will be to take risks in a risk-reward trade-off. Their decisions will be individualistic, and they may respond to the global carbon reward by mitigating carbon emissions to earn $4 \mathrm{C}$, but they may also make risk-free investments in $4 \mathrm{C}$ according to the advertised yield for 4C. $4 \mathrm{C}$ prices will respond to the "climate systemic risk," and the aggregate of the resulting mitigation actions and risk-free investing in $4 \mathrm{C}$ will create "good inefficiency" in the market economy.

The next step of the analytical verification is to check the above four relationships for time-asymmetry under the Second Law. This is the preferred verification approach because it is likely the simplest approach.

\subsection{Comparative Check for Time Asymmetry}

Verification of the RCC as the second externalized cost of carbon is based on the following check of time-asymmetry (the arrow of time) for the above four relationships. By comparing Relationship 1 with Relationship 4, it appears that these two relationships have time-asymmetry because the top-down "good efficiency" objective of the carbon tax is opposite to the bottom-up "good inefficiency" response of market actors under the carbon reward. The "good inefficiency" is a result of the risk-free investing in $4 \mathrm{C}$ and the way that market actors will respond to the climate risk even if they are unaware of the actual biophysical implications of the $4 \mathrm{C}$ price.

By comparing Relationship 2 with Relationship 3, it appears that these relationships are time-asymmetric because the top-down "risk-reducing" objective of the carbon reward is opposite to the bottom-up "risk-taking" response of individual market actors under the carbon tax.

By comparing Relationship 1 with Relationship 2, it appears that the two policies have complementary objectives, with the carbon tax improving market efficiency and the carbon reward improving climate certainty (i.e., by reducing climate systemic risk).

The policy comparisons are summarized in Table 3 . The dominant social agreements and dominant social behaviors that express time-asymmetry are those for efficiency vs. inefficiency (see Relationships $1 \& 4$ ) and taking risk vs. reducing risk (see Relationships $3 \& 2$ ). These results lend credibility to the interpretation that the 
Table 3 Summary of the epistemological translation that compares the (Type I) carbon tax with the (Type II) global carbon reward (after Chen et al. 2017)

\begin{tabular}{l|l|l}
\hline \multirow{2}{*}{ Translation } & Holistic Market Hypothesis (HMH) & (Type II) Global carbon reward \\
\cline { 2 - 3 } $\begin{array}{l}\text { Step 1. Price } \\
\text { reversal }\end{array}$ & $\begin{array}{l}\text { The authority for taxation establishes } \\
\text { a negative carbon price }\end{array}$ & $\begin{array}{l}\text { The authority for rewards estab- } \\
\text { lishes a positive carbon price }\end{array}$ \\
\hline $\begin{array}{l}\text { Step 2. Currency } \\
\text { units }\end{array}$ & $\begin{array}{l}\text { A national fiat currency provides the } \\
\text { store of value and the medium of } \\
\text { exchange. A tax instrument provides } \\
\text { the } \text { unit of account } \text { and the social } \\
\text { agreement for carbon emissions }\end{array}$ & $\begin{array}{l}\text { A parallel currency provides the } \\
\text { store of value, the medium of } \\
\text { exchange, and the unit of account. } \\
\text { A currency exchange rate mecha- } \\
\text { nism and service contracts provide } \\
\text { the social agreement for carbon } \\
\text { mitigation }\end{array}$ \\
\hline $\begin{array}{l}\text { Step 3. Arrow of } \\
\text { time (efficiency } \\
\text { vs. inefficiency) }\end{array}$ & $\begin{array}{l}\text { Relationship 1. The policy objective } \\
\text { is to promote good efficiency in the } \\
\text { marketplace by internalizing the SCC } \\
\text { into the economy with carbon taxes }\end{array}$ & $\begin{array}{l}\text { Relationship 4. Market actors } \\
\text { respond to the 4C price by miti- } \\
\text { gating carbon and making risk- } \\
\text { free investments in 4C. This pro- } \\
\text { motes good inefficiency in the } \\
\text { marketplace }\end{array}$ \\
\hline $\begin{array}{l}\text { Step 3. Arrow of } \\
\text { time (taking } \\
\text { vs. reducing risk) }\end{array}$ & $\begin{array}{l}\text { Relationship 3. Market actors respond } \\
\text { to the carbon tax and investment } \\
\text { opportunities by taking risks under } \\
\text { the risk-reward trade-off principle for } \\
\text { individuals }\end{array}$ & $\begin{array}{l}\text { Relationship 2. The policy objec- } \\
\text { tive is to reduce climate systemic } \\
\text { risk by internalizing the RCC into } \\
\text { the economy with a global carbon } \\
\text { reward }\end{array}$ \\
\hline \multicolumn{2}{|l|}{}
\end{tabular}

(Type I) negative carbon price, and the (Type II) positive carbon price have been correctly assigned time-asymmetric objectives for reducing the entropy of carbon in the environment. The results in Table 3 are further supported with a policy resolution to the temporal paradox of time discounting under systemically risky conditions (refer Sect. 5.1.3) and a possible resolution to the intractible problems of unsustainable GWP growth and unmanaged population growth (refer Sects. 5.2.2 and 5.2.3).

\section{Discussion}

The Holistic Market Hypothesis (HMH) could have major implications for climate change economics if it is found to be cogent and reliable. The following discussion is offered as a preliminary check on the hypothesis, including an interdisciplinary interpretation of the conceptual model, a proposal for experimental testing, and a solution to the temporal paradox of time discounting under systemic risk (Sect. 5.1). The utility of the global carbon reward is then discussed in terms of its compatibility with the 2015 Paris Agreement and in terms of achieving "net zero" emissions and managing economic growth (Sect. 5.2). The ethics of the new paradigm for externalized costs and "carrot and stick" policies are discussed in Sect. 5.3. 


\section{$5.1 \quad$ Theoretical Cogency}

\subsubsection{Interdisciplinary Interpretation}

Entropy is an extensive physical property that describes the "disorder" of matter that is the result of energy dissipation. In terms of living organisms and civilization, increasing entropy is often associated with decay, and locally reducing entropy is often associated with life and homeostasis. Stabilization of the climate will require limiting the concentration of GHGs in the atmosphere, and this implies that greater control over the entropy of carbon in the environment is needed. The HMH takes an interdisciplinary approach by proposing a causal link between carbon pricing, energy dissipation, and the changing entropy of carbon. This approach is unusual because few scholars have framed climate change economics in terms of entropy (e.g., Garrett 2012; Guy 2015). The standard narrative on climate change economics is founded on neoclassical assumptions (e.g., Stern 2007), and consequently most attention is given to neoclassical policies such as the carbon tax and cap-and-trade. The global carbon reward policy is unorthodox, however it addresses many common policy issues related to risk and uncertainty associated with climate change (IPCC 2014a).

A reasonable question regarding the $\mathrm{HMH}$ is this: given that standard market-based policies and regulatory approaches have successfully limited other types of pollution, such as acid rain (Chan et al. 2012), why should carbon be deserving of special treatment? Under the $\mathrm{HMH}$, carbon is assumed to be a special case because it has exceptional chemical functionality compared with other elements. This functionality includes (a) its tetravalence and ability to form a wide diversity of organic molecules, (b) its capacity to store and release chemical energy via long-chain organic molecules,

(c) its abundance on the Earth's surface, and (d) its role in storing and replicating large amounts of biological information, such as in DNA. Under the $\mathrm{HMH}$, civilization is interpreted to behave like a heat engine that is currently structured to consume fossil fuels and biofuels as dominant energy sources. This heat engine expresses the two kinds of agency mentioned in Sect. 2: (Type I) human agency and (Type II) energy dissipation. The agency of energy dissipation is overlooked in neoclassical models and policies, which tend to focus on the optimisation of economic welfare. The HMH, on the other hand, points to a need to price climate systemic risk into the financial system to effectively manage climate mitigation in response to dynamic system feedbacks and tipping points of various kinds (e.g. Steffen et al. 2018).

The HMH invites policy makers to reassess climate policies in a thermodynamic context. This may begin with the view that social agreements can influence future energy dissipation and entropy (Table 2). The $\mathrm{HMH}$ posits that all climate policies (taxes, fee-and-dividend, cap-and-trade, carbon offset trading, subsidies, etc.) are designed to reduce/limit the entropy of carbon with varying levels of stringency. Under the $\mathrm{HMH}$, the carbon tax and the global carbon reward are complementary policies because they are time-asymmetric and are likely to be optimal for improving market efficiency and climate certainty, respectively (see Table 3). 


\subsubsection{Experimental Testing}

Attempts should be made to experimentally validate the HMH. A variety of experiments and pilot projects should be developed to detect statistical differences in (a) social cooperation, (b) market efficiency, (c) climate certainty, and (d) long-term economic resilience. These tests should apply negative and positive pricing at the decision points of carbon emissions and carbon mitigation, respectively. Experiments should be designed to take into account a variety of factors, including climate sensitivity, climate and social tipping points, economic growth, primary energy supply/demand, energy return on energy invested (EROEI), innovation rates, information sharing, and market sentiment.

\subsubsection{Resolution of the Temporal Paradox}

Mark Carney $(2015,2016)$ made obvious the Tragedy of the Horizon, which refers to a temporal paradox created by society's inability to address the temporal dilemma of climate change. The dilemma is that society is weakly motivated to avoid climate damages that will occur in the distant future and by the time the damages materialize it will be too late to mitigate them. The $4 \mathrm{C}$ exchange rate mechanism can address the dilemma, because the yield on $4 \mathrm{C}$ (i.e., the time derivative of the $\mathrm{RCC}$ ) will generate a secular $4 \mathrm{C}$ bull market and preemptive transfers of financial capital into low-carbon sectors of the economy (Figs. 3 and 4). Chen (2018b) surmises that the 4C mechanism will “. . . convert tomorrow's climate risk into today's profits" to partially resolve the Tragedy of the Horizon. The temporal paradox is further examined in the following discussion of the time discounting of consumption and investments.

\section{Time Discounting of Consumption}

According to Nordhaus (2007a), Weitzman (2010), Dietz et al. (2018), and others, a conundrum has emerged concerning the time discounting of the SCC for cost-benefit analysis. The controversy involves the Ramsey formula (after Ramsey 1928) for estimating the social time discount rate, $r$, for consumption over time:

$$
r=\rho+\eta g
$$

where $r=$ social time discount rate $(\%) ; \rho=$ rate of pure time preference (\%); $\eta=$ slope of the marginal utility function for consumption (-); and $g=$ average growth rate of per capita consumption (\%).

The magnitude of $r$ strongly impacts the time discounting of the SCC which determines the ideal carbon tax. A higher $r$ may satisfy the market's desire for immediate or early consumption, but it also increases the risk of worsening climate change. The paradox is that high $r$ values (more often descriptive) and low $r$ values 
(more often prescriptive) may be proposed by stakeholders. A related question is this: if a lower $r$ provides a hedge against climate risk, then does a reduction in $r$ constitute a risk premium? Here we argue that reducing $r$ is only a pseudo risk premium, because under the Tinbergen Rule, the number of policy objectives should be matched by the same number of policy tools (Tinbergen 1952). If the objective of the carbon tax is to achieve market efficiency and a welfare maximum, then an additional tool is evidently needed to address the second objective, which is to limit the climate systemic risk (Tables 1 and 2).

A sad irony of manipulating the Ramsey formula to manage climate risk is that the approach will require international consensus on time discounting when economists, politicians, and society have diverse and sometimes contradictory views on the discount rate and taxation. The RCC metric provides an escape from the time discounting quagmire, by allowing policy makers to price risk in global financial markets using the $4 \mathrm{C}$ parallel currency. The $4 \mathrm{C}$ price and yield $-4 \mathrm{C}(t)$ and $\mathrm{Y} 4 \mathrm{C}(t)-$ are both measures of the climate systemic risk, and these metrics respond reflexively to the climate systemic risk (Sect. 3.5). 4C creates an independent price channel that is suitable for risk communication because $4 \mathrm{C}$ is immediately beneficial to market actors. Macroprudential regulation of climate change by central banks may also provide a politically stable method of managing climate risk.

Time Discounting of Investments

A formula for the time discounting of investments is the consumption based capital asset pricing model (CCAPM), after Lucas (1978):

$$
R=R_{\mathrm{f}}+\beta \pi
$$

where $R=$ investment-specific expected return adjusted for risk (\%); $R_{\mathrm{f}}=$ risk-free rate in financial markets $(\%) ; \beta=$ elasticity of climate damages with respect to changes in aggregate consumption (-); and $\pi=$ systematic or market risk premium $(\%)$.

The CCAPM formula can be used to value low-carbon projects and provide a theoretical understanding of investors' risk aversion in relation to wealth, consumption, and climate change. For example, a low-carbon project with a $\beta$ of 0 or 2 may be discounted at $1.6 \%$ or $11.2 \%$, respectively, based on a $\pi$ of $4.8 \%$ and an $R_{\mathrm{f}}$ of $1.6 \%$ (Dietz et al. 2018). The important question is whether a high insurance premium (i.e., low discounting) is justified with Eq. (9) when the investment provides climate mitigation benefits that are correlated to consumption. A difficulty of using CCAPM is that the so-called insurance premium depends on whether society will be richer or poorer in the future and knowing that higher global temperatures positively correlate with being richer. Nordhaus (2007b) acknowledges that "This leads to the paradoxical result that there is actually a negative risk premium on high climate-change outcomes" (p. 113). 
Another feature of applying CCAPM, and the traditional capital asset pricing model (CAPM), is that investors have diverse views on climate change and risk, and forcing climate-based standards for $\beta$ may prove difficult. The RCC metric can bypass these challenges by establishing a risk-free yield on $4 \mathrm{C}$ holdings - $\mathrm{Y} 4 \mathrm{C}(t)$ in foreign exchange currency markets. 4C holdings will have low sovereign and exchange rate risks, and so $4 \mathrm{C}$ trading can shift the risk-free rate of return, $R_{\mathrm{f}}$, to a new level based on an internationally agreed tolerances for climate risk (Sect. 3.5). A key benefit of introducing $4 \mathrm{C}$ is that the climate systemic risk is automatically factored into investment decisions based on $4 \mathrm{C}$ trading and investing.

\subsection{Practical Applications}

\subsubsection{The Paris Climate Agreement}

The RCC is directly relevant to the Paris Climate Agreement (UNFCCC 2015) because it can be used to set a global risk management objective. Article 2 defines the ambition of staying well below $2.0^{\circ} \mathrm{C}$ of global warming and to pursue $1.5{ }^{\circ} \mathrm{C}$ and to "...significantly reduce the risks and impacts of climate change." The Paris Agreement lacks a mechanism for setting and enforcing risk tolerances, and so no specific level of climate stabilization is actually guaranteed by the agreement. The global carbon reward can address this shortfall, but this will require a new road map for negotiating risk tolerances for climate mitigation and a concrete plan to implement the $4 \mathrm{C}$ exchange rate mechanism. A political agreement will be needed that is either an adjunct to the Paris Agreement or a separate agreement. Regardless of the details, the new policy for enforcing risk tolerances should not result in new direct taxes for citizens and businesses because the effectiveness of the new policy is strongly dependent on offering rewards and not penalties.

A peak authority will be relied upon as the macroprudential regulator of the $4 \mathrm{C}$ exchange rate mechanism (Sect. 3.4). This mechanism relates to Article 6 of the Paris Agreement by providing financial rewards anchored in market-based solutions and voluntary actions. The $4 \mathrm{C}$ exchange rate mechanism relates to Article 8, by “....reducing the risk of loss and damage. .." and by offering "Comprehensive risk assessment and management. ..." Sections 4 (a), (e), and (f) of Article 8 are most relevant, as follows:

(a) The "100-year advance 4C price alert" can address "early warning systems" (Figs. 3 and 4).

(e) The RCC can address "comprehensive risk assessment and management" (Sect. 3.4).

(f) The 4C exchange rate mechanism can address "risk insurance facilities, climate risk pooling and other insurance solutions" (Sect. 3). 


\subsubsection{Achieving Net Zero Emissions}

Limiting climate risk will require that gross world product (GWP) be decoupled from carbon emissions and that carbon emissions reduce to "net zero" in alignment with an agreed carbon budget (IPCC 2014b) that can avoid critical tipping points (e.g., Lenton 2012). To illustrate a practical application of the RCC and the $4 \mathrm{C}$ exchange rate mechanism, the problem of delivering net zero emissions is considered here when the base case is defined by conventional policies. The solution is an extension of Garrett's (2012) empirical relationship for global $\mathrm{CO}_{2}$ emissions, which assumes that a strong coupling exists between cumulative GWP and primary energy usage (refer Eqs. 1 and 2). An extended relationship is presented below based on the assumption that implementing $4 \mathrm{C}$ represents a structural change to the economy: effectively establishing a parallel economy that reduces the entropy of carbon in the environment.

When the $4 \mathrm{C}$ currency/reward is issued in the marketplace, the supply of $4 \mathrm{C}$ is proportional to $\Delta Q$, which is the annual $\mathrm{CO}_{2}$ mitigation rate that qualifies for rewards. The annual supply of the $4 \mathrm{C}$ currency, $\Delta M$, is determined from $\Delta Q$ and the unit of account, as follows:

$$
\Delta M(t)=\frac{\Delta Q(t)}{100 \mathrm{~kg} \mathrm{CO}_{2}}
$$

The revised total mass of $\mathrm{CO}_{2}$ emissions can be estimated with Eq. (1) by including GWP denominated in $4 \mathrm{C}\left(\mathrm{GWP}_{4 \mathrm{C}}\right)$ and subtracting $\Delta Q$ multiplied by $\omega$, where $\omega$ is the fraction of mitigation that is the result of the structural change to the economy for the absolute decoupling of GWP from carbon emissions. If structural decoupling is hightly effective, then $\omega$ approaches unity, but if structural decoupling is nearly impossible, then $\omega$ approaches zero. The revised mass of $\mathrm{CO}_{2}$ emissions is as follows:

$$
E(t) \cong c(t) \lambda\left\{\sum_{i=1}^{t} \mathrm{GWP}(i)+\sum_{i=k}^{t} \operatorname{GWP}_{4 \mathrm{C}}(i)\right\}-\omega(t) \Delta Q(t)
$$

where $E=$ total mass of $\mathrm{CO}_{2}$ emissions per year; $c=$ average $\mathrm{CO}_{2}$ emissions intensity of energy; $\lambda=$ average power consumption per unit of currency as a time-invariant parameter; GWP = inflation-adjusted gross world product for national economies; $\mathrm{GWP}_{4 \mathrm{C}}=\mathrm{GWP}$ for the $4 \mathrm{C}$ parallel economy; $\Delta Q=$ mitigation rate that qualifies for rewards; $\omega=$ fraction of mitigation that is decoupled from GWP; $t=$ current time in years; $i=$ time step in years; and $k=$ time step when $4 \mathrm{C}$ is introduced.

A point of technical clarification is that currency trading does not register in GWP and the issuance of $4 \mathrm{C}$ rewards does not register in $\mathrm{GWP}_{4 \mathrm{C}}$. If the $4 \mathrm{C}$ parallel currency is used to buy goods and services, then that trade with $4 \mathrm{C}$ will register in $\mathrm{GWP}_{4 \mathrm{C}}$, but if $4 \mathrm{C}$ is not used to buy goods and services and is only used to trade currencies, then $\mathrm{GWP}_{4 \mathrm{C}}$ reduces to zero. The default policy is that $4 \mathrm{C}$ is only used to trade currencies, and so $\mathrm{GWP}_{4 \mathrm{C}}$ is dropped, and Eq. (11) is rearranged to yield the 
following expression for $\Delta Q_{\text {zero, }}$, which is the quantity of mitigation rewarded by $4 \mathrm{C}$ that achieves net zero $\mathrm{CO}_{2}$ emissions:

$$
\Delta Q_{\text {zero }}(t) \cong \frac{c(t) \lambda}{\omega(t)} \sum_{i=1}^{t} \operatorname{GWP}(i)
$$

The required rate of additional mitigation, $\Delta Q_{\text {zero, }}$ is input into the Systemic Risk Abatement Cost Curve (SRACC) (Eqs. 4 and 7) to determine the 4C price that can achieve net zero emissions:

$$
4 \mathrm{C}_{\text {zero }}(t)=0.10 \times \operatorname{SRACC}\left\{\Delta Q_{\text {zero }}, t\right\}
$$

Equations (10, 12, and 13) describe the $4 \mathrm{C}$ exchange rate mechanism for delivering net zero $\mathrm{CO}_{2}$ emissions, and they also illustrate the macroeconomic approach of the global carbon reward. A negative feedback on dirty growth is established because the $4 \mathrm{C}$ price is a function of GWP (see Eqs. 12 and 13). Based on this negative feeback between the $4 \mathrm{C}$ price and GWP, and an assumed decoupling of mitigation from GWP (i.e. $\omega>0$ ), it appears plausible that the $4 \mathrm{C}$ exchange rate mechanism could provide a long-term solution to Jevons Paradox (e.g. Brookes 1990) and the Khazzoom-Brookes postulate (e.g. Saunders 1992) in relation to carbon abatement with improved energy efficiency. Additional research is needed to quantify a $4 \mathrm{C}$ price schedule that could conceivably achieve net zero emissions.

\subsubsection{Managing Global Growth}

The 4C reward/currency can be used to manage various aspects of the economy besides the average emissions intensity of energy (refer Eqs. 11 and 12). The policy opportunity is conceptualized here with a modified version of the Kaya identity, as follows:

$$
\begin{aligned}
E(t) \cong & \text { Population }(t) \times \operatorname{GWP} \text { per capita }(t) \times \mathrm{CO}_{2} \text { intensity of } \operatorname{GWP}(t) \\
& -\omega(t) \Delta Q(t)
\end{aligned}
$$

where $E=$ total mass of $\mathrm{CO}_{2}$ emissions per year ( $\mathrm{CO}_{2}$ per year); $\mathrm{GWP}=$ gross world product (USD per year); $\omega=$ fraction of additional carbon mitigation that is decoupled from GWP (-); $\Delta Q=$ additional carbon mitigation that is incentivized by the global carbon reward ( $\mathrm{CO}_{2}$ per year); and $t=$ time (year).

A major advantage of the $4 \mathrm{C}$ reward/currency is that it can be used to influence all three Kaya variables to create a negative feedback on carbon-intensive GWP, and it can also provide additional mitigation, $\omega(t) \Delta Q(t)$, that is external to the Kaya identity (compare Eqs. 11 and 14). Importantly, the 4C reward/currency could be used to incentivise government agencies to reduce human populations to below 
statistically determined baselines via socially responsible and cuturally sensitive methods.

Another important feature of the $4 \mathrm{C}$ reward/currency is that it can be used to manage average GWP per capita — and GWP growth — in a macroeconomic trade-off between climate certainty and market efficiency. This trade-off, which may be termed the inefficiency-reward trade-off after Chen et al. (2017), is based on predictable $4 \mathrm{C}$ exchange rates and risk-free investing, and it represents a possible new model for managed degrowth (van den Bergh and Kallis 2012). Returns or yields on 4C holdings/investments are risk free because they are underwritten by central banks [refer Eq. (5), Fig. 4, and Axiom E]. The 4C yield is factored into all investment decisions when the yield influences the official 'risk-free rate of return' in the global financial system (refer Sect. 5.1.3). The resulting increase in 4C holdings will place a negative feedback on spending and GWP per capita. The negative feedback is established because the $4 \mathrm{C}$ price is a function of GWP, as defined by Eqs. (12) and (13). The negative feedback on dirty GWP also creates an opportunity to improve economic welfare based on other indices. For example, the $4 \mathrm{C}$ reward rules for climate mitigation can be weighted to enhance social and ecological co-benefits that are reflected in the Inclusive Wealth Index (IWI), the Genuine Progress Indicator (GPI), and the U.N.'s Sustainable Development Goals (SGDs). These policy co-benefits give tangible meaning to the term "good inefficiency".

With respect to the first two Kaya variables (Eq. 14), the 4C reward/currency can be used to:

1. Incentivize governments to improve women's education and family planning

2. Incentivize market actors to save $4 \mathrm{C}$, thereby influencing average GWP per capita

With respect to the third Kaya variable and the additional carbon mitigation that is decoupled from GWP (Eq. 14), the 4C reward/currency can be used to:

3. Incentivize reductions in the average $\mathrm{CO}_{2}$ intensity of GWP

4. Incentivize large-scale $\mathrm{CO}_{2}$ sequestration using negative emissions technologies (NETs)

\subsection{Philosophy and Ethics}

The Holistic Market Hypothesis (HMH) appears to resolve the Tragedy of the Horizon paradoxes (Carney 2015, 2016). The keystone of the solution is the RCC as the missing complement to the SCC. If the proposed risk management approach (Eqs. 6 and 7) is acceptable to the science and economics community, then a fundamental shift may emerge in the narrative on climate change economics and ethics. This shift could be profound because the RCC may ascribe significantly greater economic value to the protection of the climate, ecosystems, people, culture, and species.

The SCC and cost-benefit analysis emerged from Pigou's (1932) tax as a pragmatic way of improving market efficiency and maximizing economic welfare: 
reflecting the ethics of neoclassical economics and anthropocentrism. The RCC and cost-effectiveness analysis described in this exposition (Tables 2 and 3) offer a new road map for managing climate systemic risk: reflecting the ethics of biophsyical economics and naturalism. Synergy provided by the internalization of the SCC and RCC (Eq. 3) might provide civilization with long-term resilience: reflecting an ethic of holism. Geo-engineering the Earth's energy balance was not considered in this exposition, and the economics and ethics of such an approach are not addressed here.

The HMH has important philosophical implications by showing that the externalized cost of carbon is influenced by the observer's worldview and choice of metrics. This is similar to Bohr's (1937) Principle of Complementarity, which asserts that an observed quantum state (kinematic or dynamic) is determined by the observer's choice of measurement. In terms of assessing and responding to climate change, an observer could adopted either a (Type I) classical/neoclassical perspective, or a (Type II) biophysical perspective. An observer with a Type II perspective may tend to focus on system dynamics and systemic risks as reported in biophysical studies (e.g., Garrett 2012), probabilistic studies (e.g., Raftery et al. 2017), and Earth system interpretations (e.g., Lenton 2012; Steffen et al. 2018). An observer with a Type I perpsective may tend to focus on standard emissions scenarios, marginal damages, welfare maximization, and mainstream policy options (e.g., Stern 2007; UNFCCC 2015).

\section{Concluding Remarks}

Climate change is still mostly an unmanaged problem, and this chapter proposes that the Holistic Market Hypothesis (HMH) of Chen et al. (2017) could be a missing link in resolving the climate crisis (refer Tables 1, 2, and 3). The hypothesis is that the Risk Cost of Carbon (RCC) is the positive externality that associates with carbon mitigation services. The RCC is equivalent to the cost of providing preventative climate insurance, and it involves no direct taxes because it is funded through monetary policy and currency trading in open markets. If the SCC and the RCC can be validated as the two externalized costs of carbon, then exciting new endeavors in environmental economics will be possible-including the monetization of climate risk and the improved management of the economy for long-term human prosperity and ecological sustainability.

A technical deduction is that a parallel currency-Complementary Currencies for Climate Change (4C) — can be used to internalize the RCC into the economy. The 4C is used to offer a global carbon reward and to price climate risk in foreign exchange currency markets. If the yield on $4 \mathrm{C}$ is risk-free, a higher risk-free rate of return will be created for investors, thereby hedging the climate risk. $4 \mathrm{C}$ should be implemented independently of taxes and cap-and-trade markets, because $4 \mathrm{C}$ will be used to retire carbon and increase the international price for carbon offset credits. An international agreement on risk tolerances and an international monetary policy are needed to 
introduce $4 \mathrm{C}$ into foreign exchange markets and to create a global price signal for the RCC. The "Global 4C" policy is proposed for this purpose.

\section{Research Recommendations}

It is recommended that the $\mathrm{HMH}$ be intensively researched. This research should involve central banks under their existing mandates or new mandates for the macroprudential regulation of climate risk. The research should be treated with urgency because the window of opportunity for achieving Article 2 of the Paris Agreement is closing (Figueres et al. 2017). Items for research include (1) developing an experimental test for the HMH (refer Sect. 5.1.2), (2) investigating a statisticalmechanical theory for the efficiency/inefficiency and risk-taking/risk-reducing asymmetries of complementary nonequilibrium carbon pricing (refer Table 3), (3) developing a model that shows how economic growth and prosperity are managed with complementary carbon pricing (refer Table 1), and (4) developing $4 \mathrm{C}$ reward rules to leverage ecosystem services (e.g., biodiversity) and social co-benefits (e.g., quality of life, employment, peace, and security). Assuming the $\mathrm{HMH}$ is correct, the research should include (5) setting a risk management base case for comparative studies, (6) estimating the RCC for the base case, (7) assessing the macroeconomic effects of the base case, (8) undertaking a feasibility study, and (9) pilot testing.

Acknowledgment There are no financial conflicts of interest to disclose. The work carried out by the authors received no financial support from the industry or government. The Global 4C Risk Mitigation policy is hosted by the Center for Regenerative Community Solutions 501(c)(3) (nonprofit), NJ 07920, USA.

\section{References}

Aglietta, M., \& Espagne, E. (2016, April). Climate and finance systemic risks, more than an analogy? The climate fragility hypothesis (30 pp.). Working Paper CEPII, No 2016-10.

Andreoni, J., Harbaugh, W., \& Vesterlund, L. (2003). The carrot or the stick: Rewards, punishments, and cooperation. American Economic Review, 93(3), 893-902.

Annila, A., \& Salthe, S. (2009). Economies evolve by energy dispersal. Entropy, 11, 606-633.

Bohr, N. (1937). Causality and complementarity. Philosophy of Science, 4(3), 289-298.

Boltzmann, L. (1872). Weitere Studien über das Wärmegleichgewicht unter Gasmolekülen. Sitzungsberichte Akademie der Wissenschaften, 66, 275-370.

Broadbent, J., \& Vaughter, P. (2014). Inter-disciplinary analysis of climate change and society: A network approach, Chapter 10. In M. J. Manfredo, J. J. Vaske, A. Rechkemmer, \& E. A. Duke (Eds.), Understanding society and natural resources. Heidelberg: Springer.

Brookes, L. (1990). Energy efficiency and the greenhouse effect. Energy and Environment, 1(4), 318-333. 
Carney, M. (2015, September 29). Breaking the tragedy of the horizon-Climate change and financial stability. Speech given by the Governor of the Bank of England, Chairman of the Financial Stability Board, Lloyd's of London.

Carney, M. (2016, September 22). Resolving the climate paradox. Speech given by the Governor of the Bank of England, Chair of the Financial Stability Board, Arthur Burns Memorial Lecture, Berlin.

Chan, G., Stavins, R., Stowe, R., \& Sweeney, R. (2012). The $\mathrm{SO}_{2}$ allowance trading system and the clean air act amendments of 1990: Reflections on twenty years of policy innovation. Cambridge, MA: Harvard Environmental Economics Program.

Chen, D. B. (2018a). Utility of the blockchain for climate mitigation. The Journal of British Blockchain Association, 1(1), 1-9.

Chen, D. B. (2018b). Central banks and blockchains: The case for managing climate risk with a positive carbon price, Chapter 15. In A. Marke (Ed.), Transforming climate finance and green investment with blockchains. Amsterdam: Elsevier.

Chen, D. B., van der Beek, J., \& Cloud, J. (2017). Climate mitigation policy as a system solution: Addressing the risk cost of carbon. Journal of Sustainable Finance \& Investment, 7(3), 1-42.

Chen, X., Sasaki, T., Brännström, Å., \& Dieckmann, U. (2015). First carrot, then stick: How the adaptive hybridization of incentives promotes cooperation. Journal Royal Society Interface, 12, 20140935.

Clausius, R. (1854). Ueber eine veränderte Form des zweiten Hauptsatzes der mechanischen Wärmetheoriein. Annalen der Physik und Chemie, 93(12), 481-506.

Clausius, R. (1867). The mechanical theory of heat - With its applications to the steam engine and to physical properties of bodies. London: John van Voorst.

Cleveland, C. J. (1987). Biophysical economics: Historical perspective and current research trends. Ecological Modelling, 38(1-2), 47-73.

Currarini, S., Marchiori, C., \& Tavoni, A. (2014). Network economics and the environment: Insights and perspectives. Centre for Climate Change Economics and Policy, Working Paper No. 162; Grantham Research Institute on Climate Change and the Environment, Working Paper No. 145 .

Dietz, S., Gollier, C., \& Kessler, L. (2018). The climate beta. Journal of Environmental Economics and Management, 87, 258-274.

Eisenstein, C. (2011). Sacred economics: Money, gift, and society in the age of transition. Paperback.

England, J. (2013). Statistical physics of self-replication. The Journal of Chemical Physics, 139, 121923

Figueres, C., Schellnhuber, H. J., Whiteman, G., Rockström, J., Hobley, A., \& Rahmstorf, S. (2017). Three years to safeguard our climate. Nature, 546(7660), 593-595.

Fuss, S., Canadell, J. G., Peters, G. P., Tavoni, M., Andrew, R. M., Ciais, P., et al. (2014). Betting on negative emissions. Nature Climate Change, 4(10), 850-853.

Garrett, T. J. (2011). Are there basic physical constraints on future anthropogenic emissions of carbon dioxide? Climatic Change, 104, 437-455.

Garrett, T. J. (2012). No way out? The double-bind in seeking global prosperity alongside mitigated climate change. Earth System Dynamics, 3, 1-17.

Garrett, T. J. (2014). Long-run evolution of the global economy: 1. Physical basis. Earth's Future, 2 (3), 127-151.

Garrett, T. J. (2015). Long-run evolution of the global economy: 2. Hindcasts of innovation and growth. Earth System Dynamics Discussions, 6(1), 673-688.

Gasser, T., Guivarch, G., Tachiiri, K., Jones, C. D., \& Ciais, P. (2015). Negative emissions physically needed to keep global warming below $2^{\circ} \mathrm{C}$. Nature Communications, 6, 7958.

Guy, D. (2015). Energy consumption and entropy release in the biosphere. Encyclopédie de l'énergie. Accessed June 18, 2018, from http://encyclopedie-energie.org/articles/energy-con sumption-and-entropy-release-biosphere 
Hansen, J., Kharecha, P., Sato, M., Masson-Delmotte, V., Ackerman, F., Beerling, D. J., et al. (2013). Assessing 'dangerous climate change': Required reduction of carbon emissions to protect young people, future generations and nature. PLoS One, 8(12), e81648.

Hilbe, C., \& Sigmund, K. (2010). Incentives and opportunism: From the carrot to the stick. Proceedings of the Royal Society B: Biological Sciences, 277(1693), 2427-2433.

IAWG. (2013). Technical support document: Technical update of the social cost of carbon for regulatory impact analysis under executive order 12866. 1-22 (US government).

IPCC. (2013). In T. F. Stocker, D. Qin, G.-K. Plattner, M. Tignor, S. K. Allen, J. Boschung, et al. (Eds.), Climate change 2013: The physical science basis. Contribution of working group I to the fifth assessment report of the intergovernmental panel on climate change (p. 1535). Cambridge: Cambridge University Press.

IPCC. (2014a). Integrated risk and uncertainty assessment of climate change response policies. In O. Edenhofer, R. Pichs-Madruga, Y. Sokona, E. Farahani, S. Kadner, K. Seyboth, et al. (Eds.), Climate change 2014: Mitigation of climate change. Contribution of working group III to the fifth assessment report of the intergovernmental panel on climate change. Cambridge: Cambridge University Press.

IPCC. (2014b). In R. K. Pachauri \& L. A. Meyer (Eds.), Climate change 2014: Synthesis report. Contribution of working groups I, II and III to the fifth assessment report of the intergovernmental panel on climate change (p. 151). Geneva: IPCC.

IPCC. (2014c). Social, economic and ethical concepts and methods. In O. Edenhofer, R. PichsMadruga, Y. Sokona, E. Farahani, S. Kadner, K. Seyboth, et al. (Eds.), Climate change 2014: Mitigation of climate change. Contribution of working group III to the fifth assessment report of the intergovernmental panel on climate change. Cambridge: Cambridge University Press.

ISO. (2009). ISO Guide 73:2009 Risk management - Vocabulary. Accessed July 28, 2017, from http://www.iso.org/iso/home/standards/iso31000.htm

Jevons, W. S. (1875). Money and the mechanism of exchange. New York: D. Appleton. Library of Economics and Liberty. Accessed March 28, 2018, from http://www.econlib.org/library/ YPDBooks/Jevons/jvnMME24.html

Keynes, J. M. (1921). Treatise on probability. London: Macmillan. Accessed July 28, 2016, from http://archive.org/stream/treatiseonprobab007528mbp\#page/n11/mode/2up

Knight, F. H. (1921). Risk, uncertainty and profit. New York: Hart, Schaffner and Marx.

Kümmel, R., \& Lindenberger, D. (2014). How energy conversion drives economic growth far from the equilibrium of neoclassical economics. New Journal of Physics, 16(2014), 125008.

Law, J. (2009). Actor network theory and material semiotics, Chapter 7. In B. S. Turner (Ed.), Social theory. Oxford: Wiley-Blackwell.

Lawrence, S., Liu, Q., \& Yakovenko, V. M. (2013). Global inequality in energy consumption from 1980 to 2010. Entropy, 15, 5565-5579.

Lenton, T. M. (2012). Arctic climate tipping points. Ambio, 41(1), 10-22.

Lucas, R. E. (1978). Asset prices in an exchange economy. Econometrica, 46, 1429-1445.

Maxwell, J. C. (1860). II. Illustrations of the dynamical theory of gases. The London, Edinburgh, and Dublin Philosophical Magazine and Journal of Science, $20(130), 1860$.

Milnes, A. (1919). The economic foundations of reconstruction. London: Macdonald and Evans.

Nordhaus, W. D. (1991). To slow or not to slow: The economics of the greenhouse effect. The Economic Journal, 101(407), 920-937.

Nordhaus, W. D. (2007a). A review of the stern review on the economics of climate change. Journal of Economic Literature, 45(3), 686-702.

Nordhaus, W. D. (2007b, July 24). The challenge of global warming: Economic models and environmental policy. William Nordhaus Sterling Professor of Economics, Yale University, New Haven, CT.

Nordhaus, W. D. (2017). Revisiting the social cost of carbon. PNAS, 114(7), 1518-1523.

Oster, G., Perelson, A., \& Katchalsky, A. (1971). Network thermodynamics. Nature, 234, 393-399.

Pigou, A. C. (1932). The economics of welfare, 1920. London: MacMillan. 
Raftery, A. E., Zimmer, A., Frierson, D. M., Startz, R., \& Liu, P. (2017). Less than $2^{\circ} \mathrm{C}$ warming by 2100 unlikely. Nature Climate Change, 7, 637-641.

Ramsey, F. (1928). A mathematical theory of saving. Economic Journal, 38(152), 543-559.

Raworth, K. (2017). Doughnut economics: Seven ways to think like a 21 st-century economist (p. 320). White River Junction, VT: Chelsea Green Publishing.

Robbins, L. (1935). An essay on the nature and significance of economic science. London: Macmillan.

Saunders, H. D. (1992). The Khazzoom-Brookes postulate and neoclassical growth. The Energy Journal, 13(4), 131-148.

Shapiro, A. F., \& Koissi, M.-C. (2015). Risk assessment applications of fuzzy logic (p. 112). Casualty Actuarial Society, Canadian Institute of Actuaries, Society of Actuaries.

Sirkis, A., Hourcade, J. C., Dasgupta, D., Studart, R., Gallagher, K., Perrissin-Fabert, B., et al. (2015). Moving the trillions: A debate on positive pricing of mitigation actions. Nogent-surMarne: Centro Brasil no Clima Ed./CIRED.

Stern, N. (2007). The economics of climate change: The stern review. Cambridge: Cambridge University Press.

Steffen, W., Rockström, J., Richardson, K., Lenton, T. M., Folke, C., Liverman, D., Summerhayes, C. P., Barnosky, A. D., Cornell, S. E., Crucifix, M., Donges, J. F., Fetzer, I., Lade, S. J., Scheffer, M., Winkelmann, R., \& Schellnhuber, H. J. (2018). Trajectories of the earth system in the Anthropocene. Proceedings of the National Academy of Sciences, 115(33), 8252-8259.

Tinbergen, J. (1952). On the theory of economic policy. Volume 1 of contributions to economic analysis. Amsterdam: North-Holland.

U.S. President. (1981). 'Federal Regulation'. Exec. Order No. 12291 of Feb. 17, 1981, Federal Register 46, Document citation: 46 FR 13193, 3 CFR, 1981 Comp., (p. 127).

UNFCCC. (2015). United Nations. In Adoption of the Paris Agreement, 21st Conference of the Parties. Report No. FCCC/CP/2015/L.9/Rev.1. Paris.

van den Bergh, J. C. J. M., \& Kallis, G. (2012). Growth, a-growth or degrowth to stay within planetary boundaries? Journal of Economic Issues, 46(4), 909-920.

Weitzman, M. L. (2010). Risk-adjusted gamma discounting. Journal of Environmental Economics and Management, 60(1), 1-13.

Open Access This chapter is licensed under the terms of the Creative Commons Attribution 4.0 International License (http://creativecommons.org/licenses/by/4.0/), which permits use, sharing, adaptation, distribution and reproduction in any medium or format, as long as you give appropriate credit to the original author(s) and the source, provide a link to the Creative Commons license and indicate if changes were made.

The images or other third party material in this chapter are included in the chapter's Creative Commons license, unless indicated otherwise in a credit line to the material. If material is not included in the chapter's Creative Commons license and your intended use is not permitted by statutory regulation or exceeds the permitted use, you will need to obtain permission directly from the copyright holder.

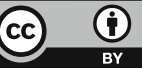

